\title{
Europa Clipper Preliminary Design Review Propellant Slosh Analysis
}

\author{
Emily A. Beckman, ${ }^{1}$ David J. Benson ${ }^{2}$, Daniel J. Cataldo ${ }^{3}$, and Wanyi W. $\mathrm{Ng}^{4}$ \\ Goddard Space Flight Center, Greenbelt, Maryland, 20771, USA
}

\begin{abstract}
Propellant slosh was analyzed for both the oxidizer and the fuel for the Europa Clipper propulsion system. Slosh was examined for various fill fractions for cases where acceleration was on the order of magnitude of $10^{-2} \mathrm{~m} / \mathrm{s}^{2}$ using the computational fluid dynamics software package STAR-CCM+ and at various fill fractions for cases where acceleration was on the order of magnitude of $10^{-5} \mathrm{~m} / \mathrm{s}^{2}$ using Surface Evolver. Equivalent mechanical model parameters were derived from the CFD data using MATLAB for both the higher and the lower acceleration slosh cases. These parameters were plotted and can be used to interpolate mechanical model parameters at fill fractions not analyzed by CFD or Surface Evolver.
\end{abstract}

\section{Introduction}

SLOSH is the movement of a liquid within a container. Spacecraft propulsion systems must deal with this phenomenon because liquid propellants will slosh within tanks throughout the course of the mission. While this movement is often periodic, some slosh may be non-periodic due to a non-periodic input movement, or because there is no settling acceleration. This paper focuses on deriving models for periodic slosh.

The Europa Clipper spacecraft will travel to and enter orbit around Jupiter where it will complete multiple flybys of the moon, Europa. Europa shows evidence of a liquid ocean under a sheet of icy crust. To complete the important scientific objectives of the mission, the spacecraft must be capable of remaining stable during maneuvers. Fuel slosh can cause the spacecraft to be subjected to forces and moments which must be understood to maintain stability and maximize maneuver efficiency. If the attitude control system cannot appropriately account for slosh behavior, scientific observation time may be lost, excess propellant may be used to maintain stability, or in the worst-case scenario, the spacecraft may spin out of control. Slosh may also be excited by the attitude control system. This must be prevented for the same reasons.

While physical testing is preferred, slosh testing at flight accelerations is not possible in a terrestrial environment and sub-orbital or orbital testing is prohibitively expensive both in time and money. Instead of using physical testing, propellant slosh is modeled using computational fluid dynamics (CFD). NASA Goddard Space Flight Center uses the Siemens owned STAR-CCM+ code. CFD is an effective tool for modeling slosh in which the surface tension is not the dominant physics in the model. In cases with a Bond number significantly greater than one, settling accelerations are high enough to dominate the physics of the slosh and are classified as high-g.

For cases in which the Bond number is significantly less than one, surface tension dominates and Surface Evolver is used to model the slosh. Surface Evolver is a code developed under the Geometry Supercomputing Project [1] and was used for the Cassini mission to model slosh under a low acceleration environment [2]. In this paper, slosh under accelerations on the order of magnitude of $10^{-5} \mathrm{~m} / \mathrm{s}^{2}$ will be referred to as low-g slosh and under accelerations on the order of magnitude of $10^{-2} \mathrm{~m} / \mathrm{s}^{2}$ will be referred to as high-g slosh. Surface Evolver is a steady state code and therefore does not output time accurate results. To overcome this limitation, a series of steady state models are run at different lateral accelerations.

Because CFD is computationally expensive and because Surface Evolver is a steady state code, equivalent mechanical models are used when testing attitude control systems. These models can be damped pendulums or springmass-damper systems. It is also possible to combine the two types of models. Pendulum models allow the sloshing frequency to be a function of settling acceleration and they also allow for center of mass movement in the vertical as well as the horizontal direction. The spring-mass-damper models are generally simpler to derive, but the frequency is

\footnotetext{
${ }^{1}$ Intern, Code 597, AIAA Student Member

${ }^{2}$ Propulsion Engineer, Code 597

${ }^{3}$ Intern, Code 597

${ }^{4}$ Propulsion Pathways Intern, Code 597, AIAA Student Member
} 
dependent on the spring constant and so there is no readily available equation to relate the settling acceleration to the frequency [3]. The pendulum model is used in this paper and the derivation approach used is detailed in Ref. [3].

\section{Geometry}

The geometry studied in this paper is a preliminary design for both the Europa Clipper tank and propellant management device (PMD) as shown in Figure 1. The mechanical design of the PMD is beyond the scope of this paper.

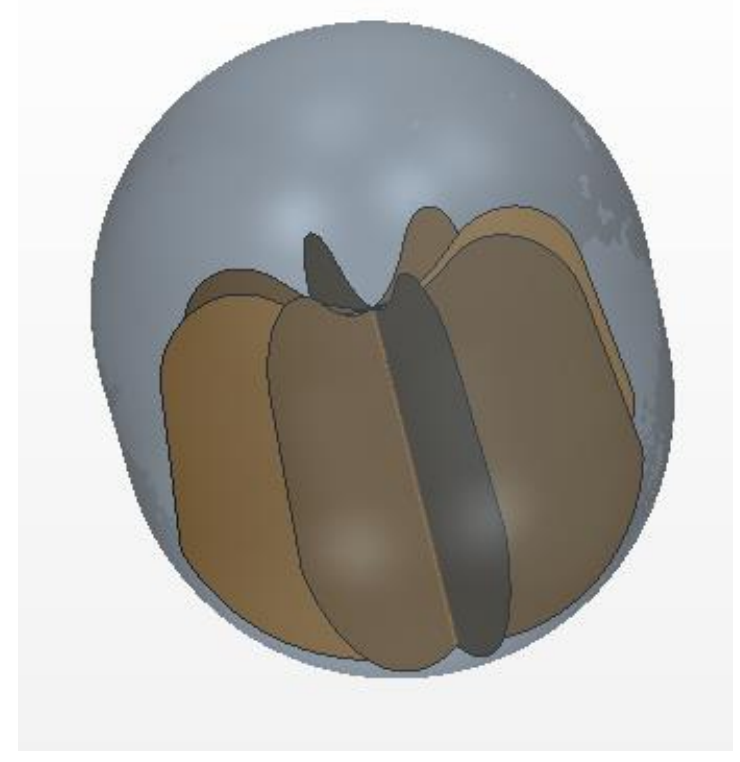

Fig. 1 Tank and PMD geometry.

\section{High-G Cases}

\section{A. CFD Model Setup}

STAR-CCM+ was used to perform the high-g CFD slosh analysis for Europa Clipper. The CFD software provides the propellant center of mass, the forces on the tank and PMD, the moment on the tank and PMD during the sloshing event, and the moment of inertia of the settled propellant. This program has been used successfully in the past by NASA Goddard Space Flight Center to model slosh for the ICESat-2 and OSIRIS-Rex missions.

The propellants used for the Europa Clipper mission are monomethylhydrazine (MMH) fuel and dinitrogen tetroxide (NTO) oxidizer. The propellant properties are calculated from equations provided in the United States Air Force handbooks on hydrazine fuels and nitrogen tetroxide oxidizers [4]. For a given temperature, the equations provide surface tension, density, and viscosity.

A polyhedral mesh with prism cells at the walls was created within STAR-CCM+. A mesh independence analysis was done to ensure that the mesh was of a sufficient quality and refinement to get accurate results. Table 1 summarizes the mesh independence study results and gives the percent difference between each mesh and the finest mesh for three parameters of interest. Cell counts of $116 \mathrm{k}, 250 \mathrm{k}, 400 \mathrm{k}, 500 \mathrm{k}$, and $700 \mathrm{k}$ cells were examined. The y-direction is the transverse direction and the z-direction is the axial direction. The 400,000-cell mesh was chosen for modeling as it allows CFD modeling of a case within 48 hours with sufficient mesh refinement. 
Table 1. Convergence of mesh.

\begin{tabular}{|c|c|c|c|c|c|}
\hline Cell Count & $\begin{array}{c}\text { Acceleration } \\
\left(\mathrm{m} / \mathrm{s}^{2}\right)\end{array}$ & Mesh Type & $\begin{array}{c}\text { Avg \% Diff } \\
\text { from Finest } \\
\text { Mesh CMy }\end{array}$ & $\begin{array}{c}\text { Avg \% Diff } \\
\text { from Finest } \\
\text { Mesh Fy }\end{array}$ & $\begin{array}{c}\text { Avg \% Diff from } \\
\text { Finest Mesh } \\
\text { Mx }\end{array}$ \\
\hline $116 \mathrm{k}$ & 0.067 & Polyhedral & 31.57 & 140.31 & 233.61 \\
\hline $250 \mathrm{k}$ & 0.067 & Polyhedral & 11.32 & 6.44 & 8.86 \\
\hline $400 \mathrm{k}$ & 0.067 & Polyhedral & 4.32 & 4.23 & 3.36 \\
\hline $500 \mathrm{k}$ & 0.067 & Polyhedral & 2.66 & 2.29 & 1.88 \\
\hline
\end{tabular}

The liquid surface is initialized at 5 degrees from horizontal. When deriving the pendulum parameters, the liquid surface offset angle is also assumed to be the pendulum initial offset angle. Figure 2 shows what a surface offset of 5 degree looks like at different fill fractions. A constant settling acceleration is applied using STAR-CCM+'s gravity model.

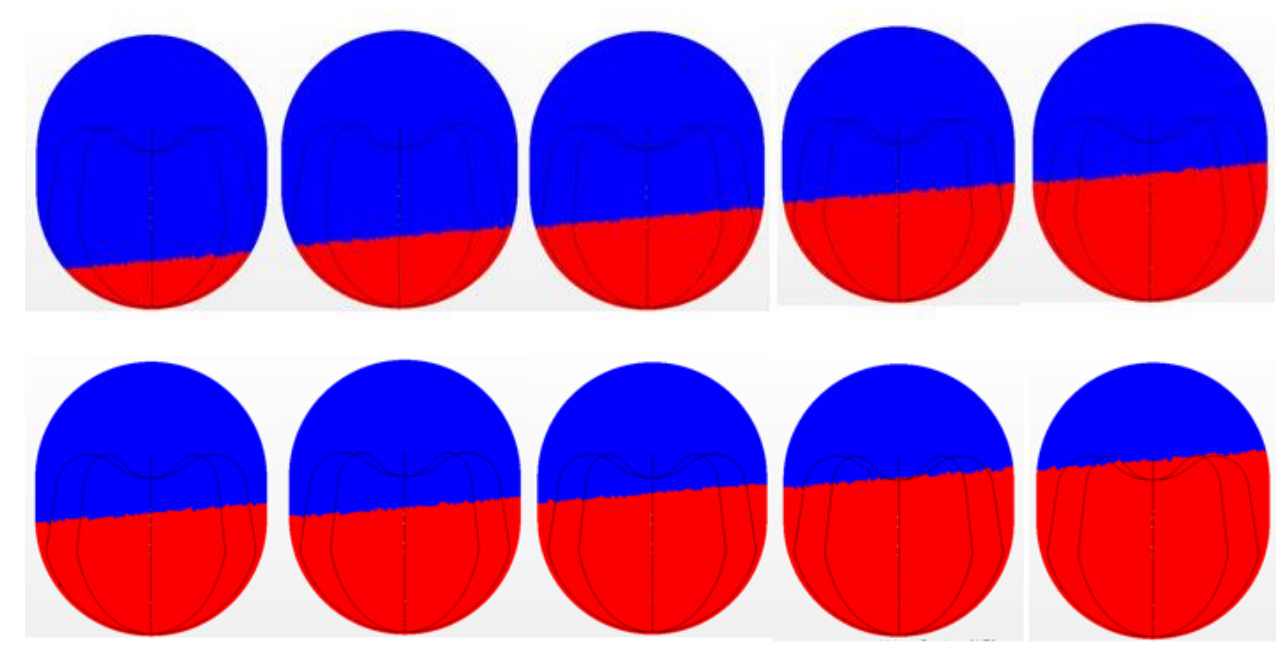

Fig. 2 Initial position of NTO propellant. Fill fraction of 0.1, 0.2, 0.3, 0.4, 0.5, 0.5, 0.5, 0.6, 0.7, 0.8.

The moments and moments of inertia use the center of the tank as the reference point, which is also the origin of the coordinate system. The acceleration is in the negative $\mathrm{z}$-direction (down in Figure 2).

Inner iterations were stopped after 30 iterations, or after 5 minimum inner iterations if the standard deviation of the inner iterations are less than 1e-4 N. The residuals were below 1e-7. STAR-CCM+ tracks mass continuity, NTO, $\mathrm{MMH}, \mathrm{x}$-momentum, y-momentum, and z-momentum.

\section{B. CFD Results}

The CFD results used to derive pendulum parameters were the center of mass, the force exerted on the tank, and the moment exerted on tank. The results in Figures 3-5 are only for NTO. The shape of the curves are nearly identical for MMH, but the magnitudes of the center of mass movement, forces, and moments are less because MMH is less dense than NTO. 


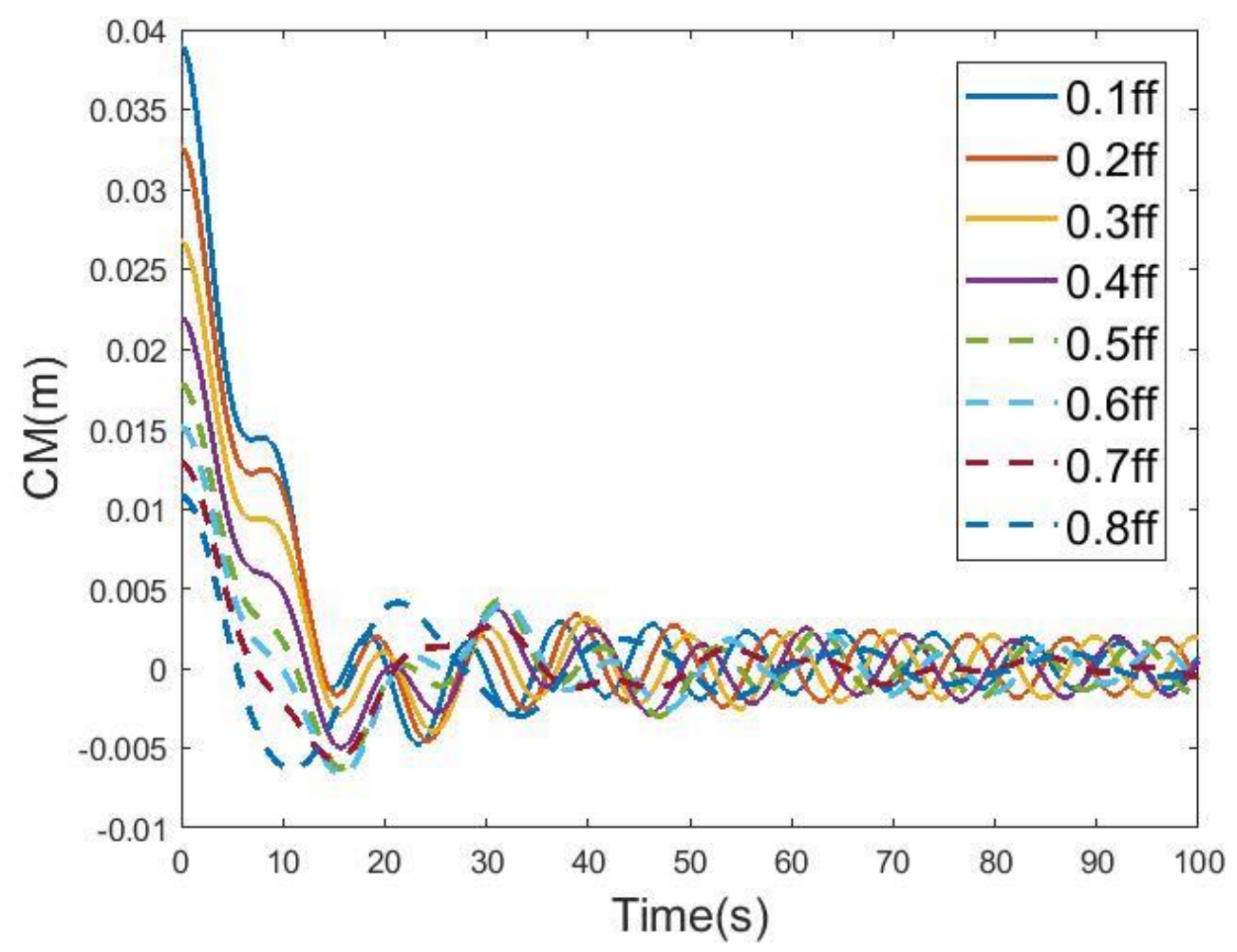

Fig. 3 NTO CFD center of mass results in principal sloshing direction.

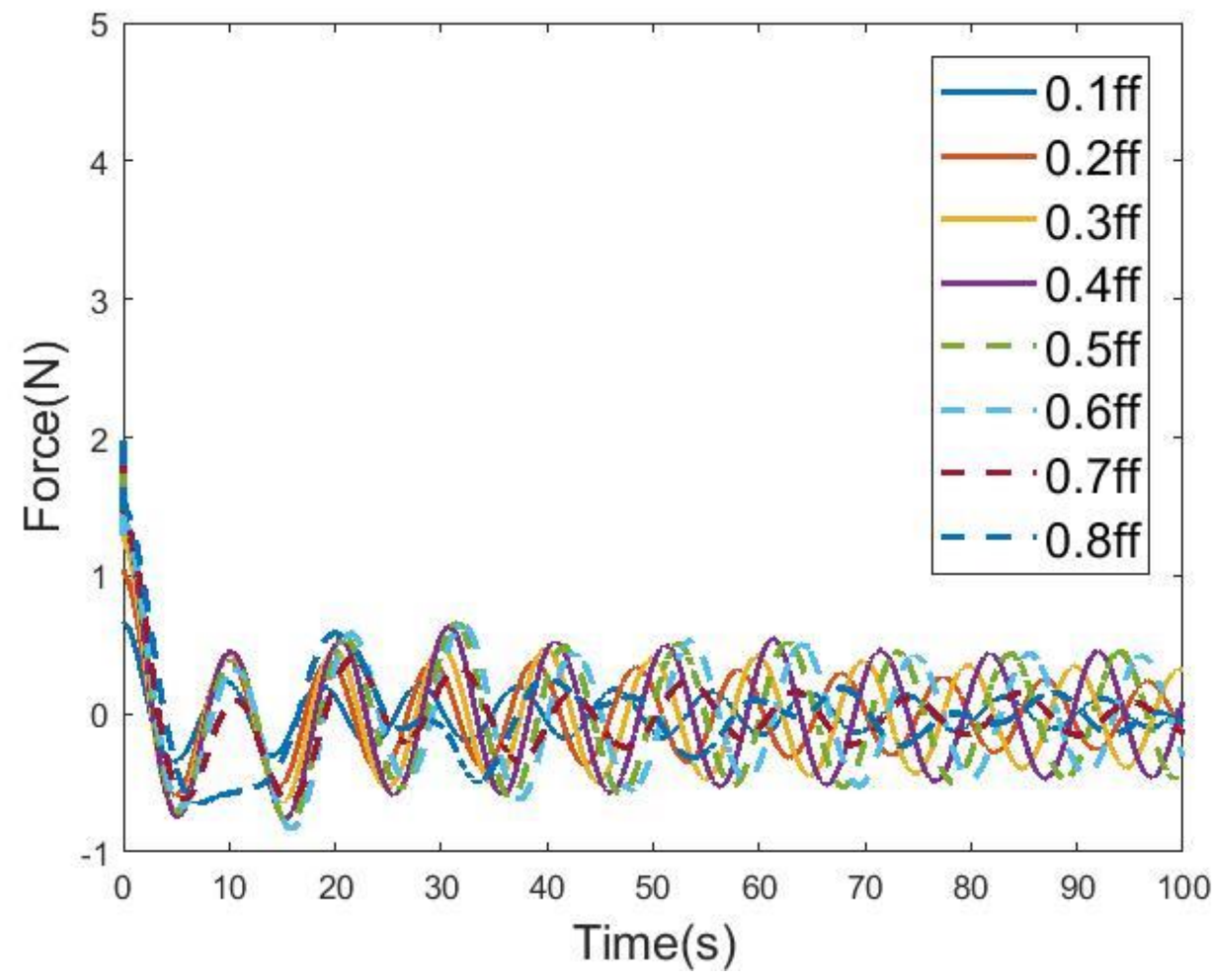

Fig. 4 NTO CFD force results. 


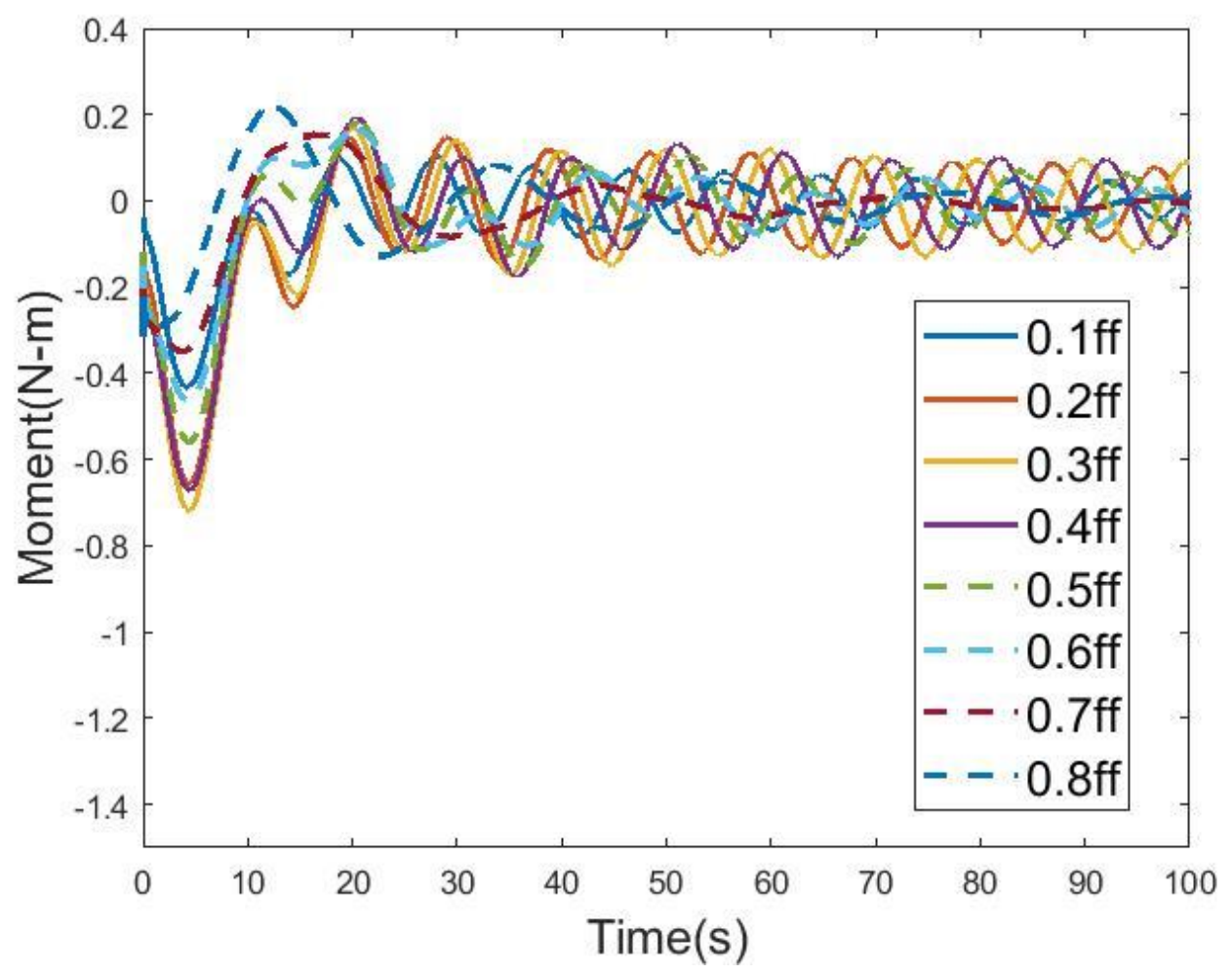

Fig. 5 NTO CFD moment results.

\section{Pendulum Parameters}

The mechanical model used for the high-g cases was a system of two linearly damped pendulums and a static mass, as illustrated in Figure 6. Two pendulums are needed in order to model the contributions of both full tank and sector slosh. Full tank slosh is the general movement of the fluid from one side of the tank to the other. Sector slosh is the slosh which occurs between the vanes of the PMD. While in actuality the fluid is not two separate volumes that are behaving independently of each other, classifying the slosh as constituent components of full tank and sector slosh aids in the analysis and describes the resulting total slosh well [3].

The output of the CFD model was input into a MATLAB program which, using the equations of motion for the mechanical system, optimized pendulum parameters to reduce the difference in center of mass location between the CFD results and the mechanical model [5]. The quality of fit was determined in part by the user's choice of two starting points. Forces in each model had similar quality of match to that of the center of mass, so no further modification was required to match forces. The moments on the tank were matched by adjusting pendulum length manually until the error was minimized. A case with low error between the mechanical and CFD models is shown in Figures 7-9.

This process was repeated for various fill fractions and the results are given in Table 2. The MATLAB parameter matching process was performed twice. As previously noted, user choice played a part in the quality of the match between the CFD and mechanical model results because the MATLAB code ran based on initial points selected by the user. For this reason, the variability in results due to code input was studied to determine the uncertainty introduced by user choice. Table 2 gives a summary of the variability in addition to the parameters used in finding trends. For each case, the percent difference between the parameter set used in developing trends and the alternate parameter set are shown below the case in a gray row. 


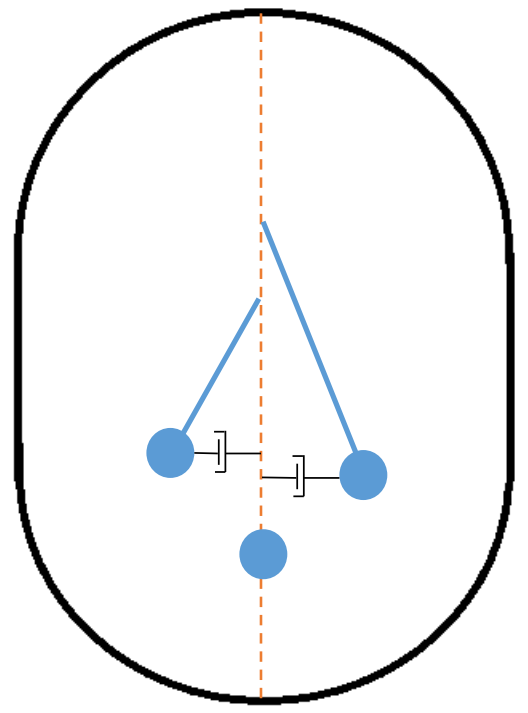

Fig. 6 Pendulum model for high-g cases. Two linearly damped pendulums with a static mass all attached at the tank centerline.

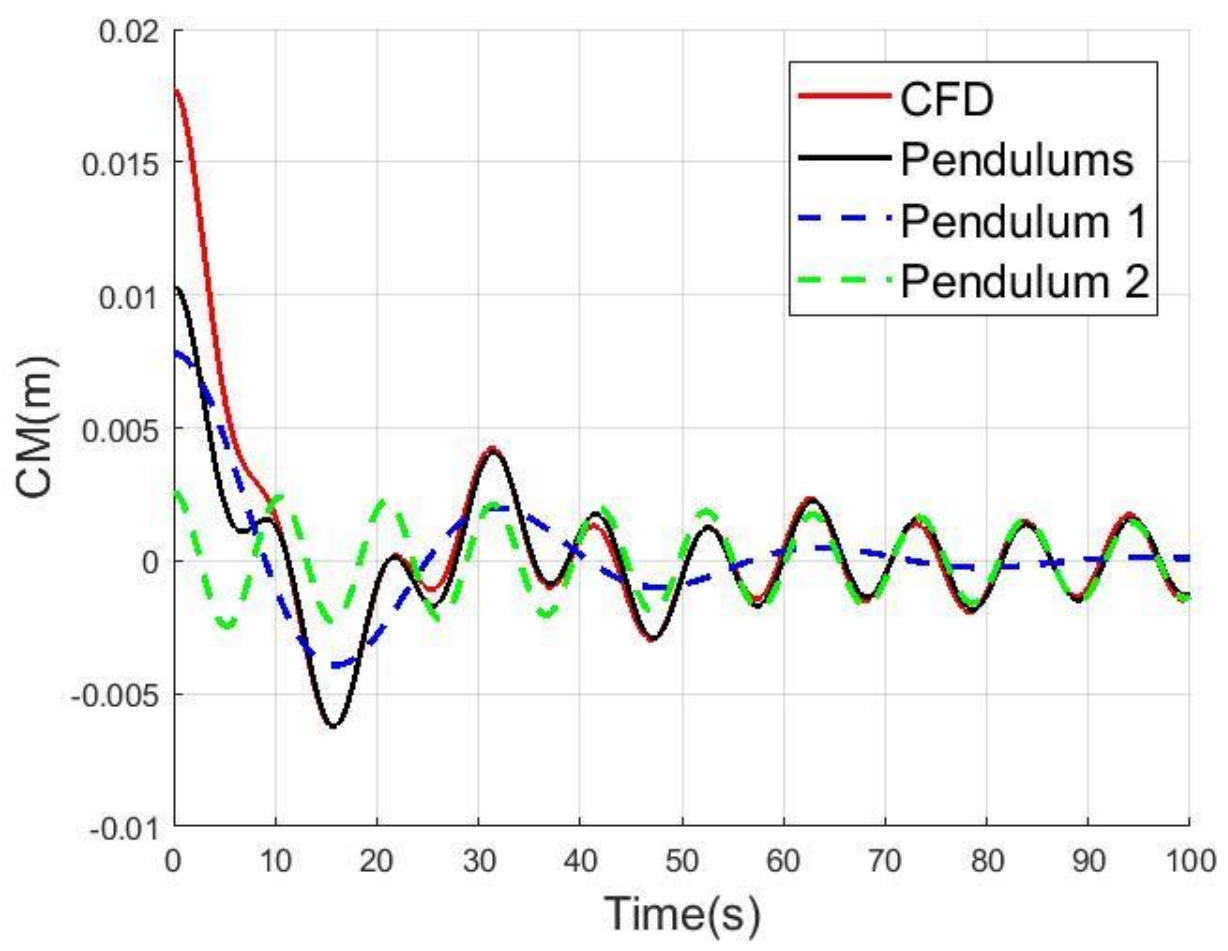

Fig. 7 Center of mass data for NTO at 0.5 fill fraction and $0.059 \mathrm{~m} / \mathrm{s}^{2}$ settling acceleration. 


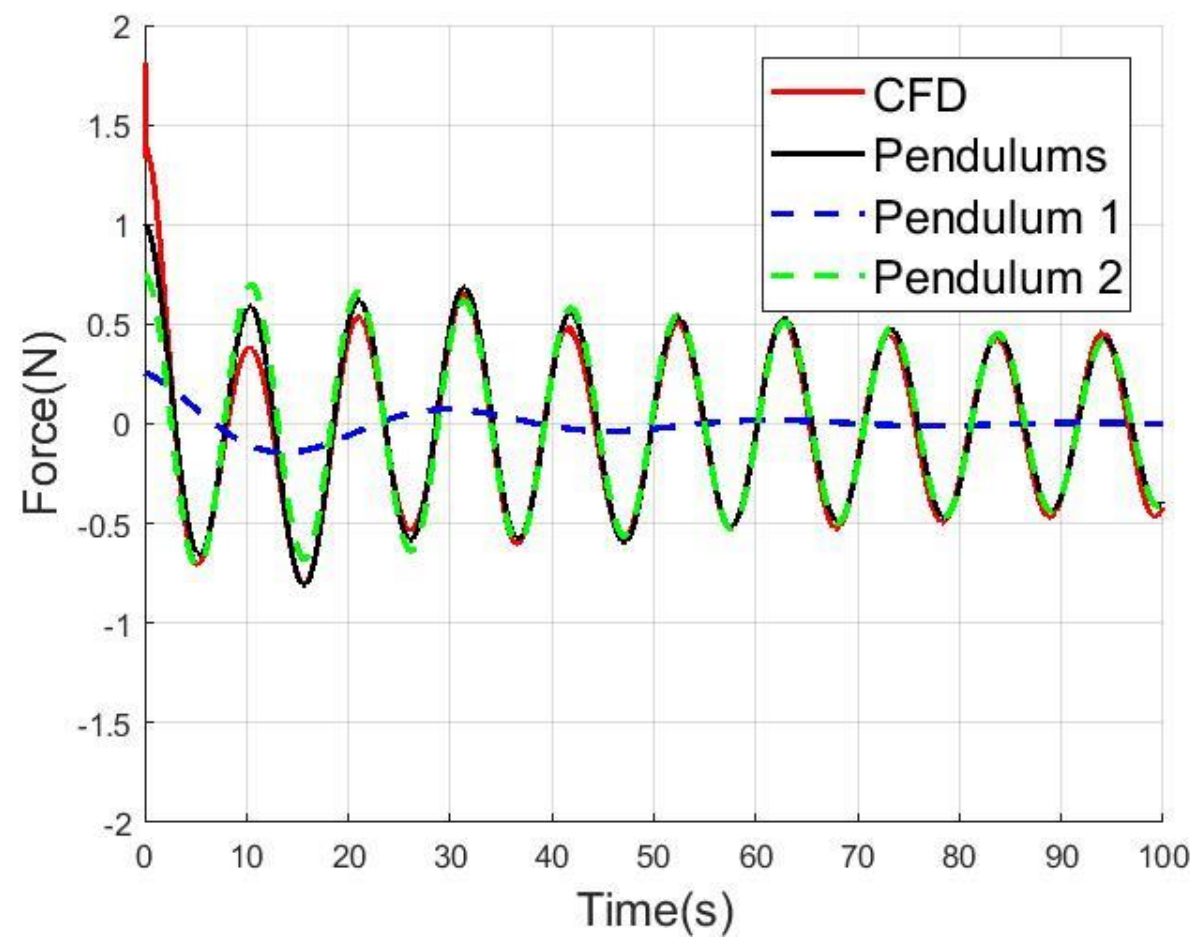

Fig. 8 Force data for NTO at 0.5 fill fraction and $0.059 \mathrm{~m} / \mathrm{s}^{2}$ settling acceleration.

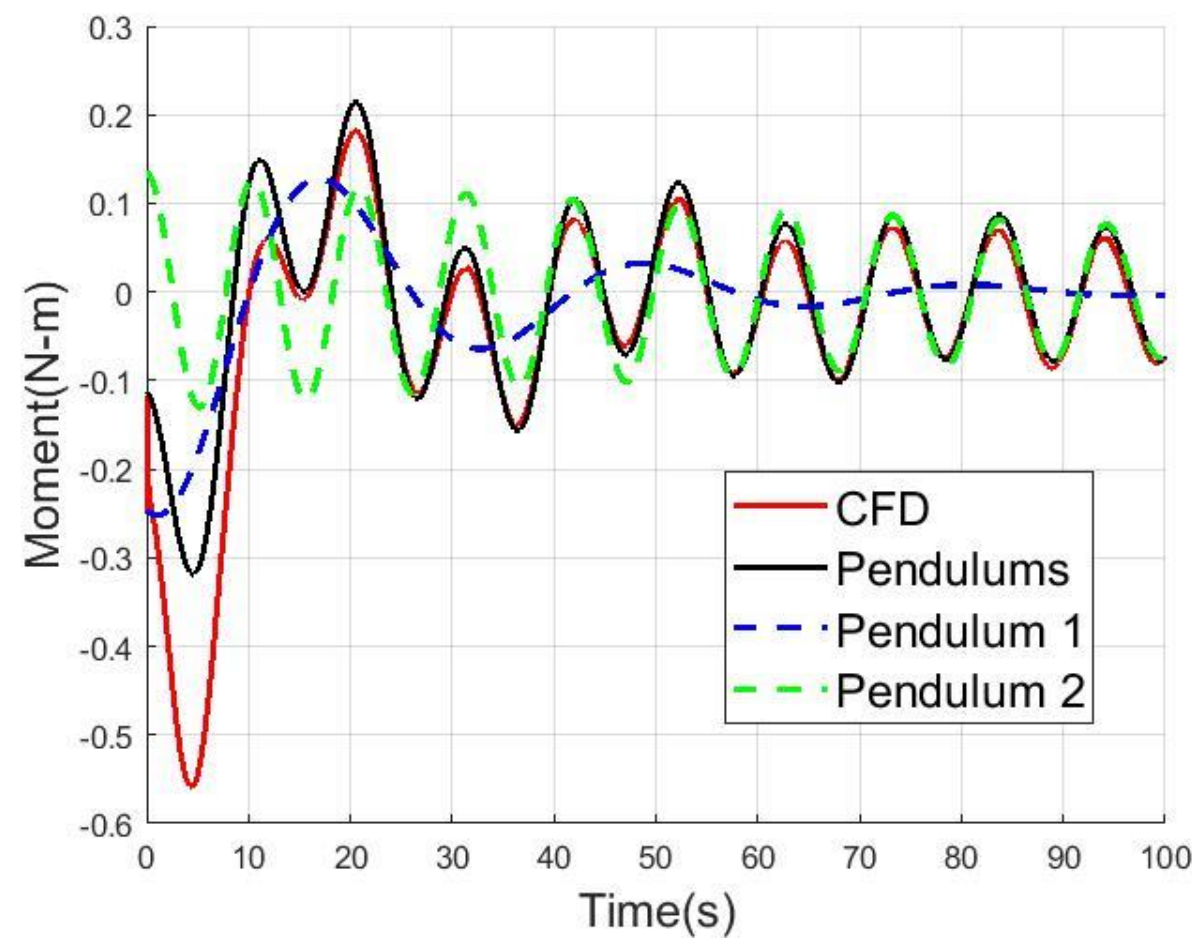

Fig. 9 Moment data for NTO at 0.5 fill fraction and $0.059 \mathrm{~m} / \mathrm{s}^{2}$ settling acceleration. 
Table 2 Parameters for high acceleration cases with percent difference between users for each parameter in light gray.

\begin{tabular}{|c|c|c|c|c|c|c|c|c|c|c|c|c|c|c|c|}
\hline \multicolumn{2}{|c|}{ Case } & \multicolumn{5}{|c|}{ Pendulum for Full-Tank Mode } & \multicolumn{5}{|c|}{ Pendulum for Sector Mode } & \multicolumn{4}{|c|}{ Static Mass } \\
\hline $\begin{array}{c}\text { Fill } \\
\text { Fraction }\end{array}$ & Propellant & $\begin{array}{c}\text { Mass } \\
(\mathrm{kg})\end{array}$ & \begin{tabular}{|c} 
Length \\
$(\mathrm{m})$
\end{tabular} & $\begin{array}{l}\text { Hinge Point } \\
\text { (m) }\end{array}$ & $\begin{array}{c}\text { Frequency } \\
(\mathrm{Hz})\end{array}$ & \begin{tabular}{|c} 
Damping Ratio \\
(\%)
\end{tabular} & $\begin{array}{c}\text { Mass } \\
(\mathrm{kg})\end{array}$ & $\begin{array}{l}\text { Length } \\
(\mathrm{m})\end{array}$ & $\begin{array}{c}\text { Hinge Point } \\
\text { (m) }\end{array}$ & $\begin{array}{c}\text { Frequency } \\
(\mathrm{Hz})\end{array}$ & $\begin{array}{c}\text { Damping Ratio } \\
\text { (\%) }\end{array}$ & $\begin{array}{c}\text { Mass } \\
(\mathrm{kg})\end{array}$ & \begin{tabular}{|c} 
Hinge Point \\
(m)
\end{tabular} & $\begin{array}{c}\text { Transverse } \\
\text { Inertia }\left(\mathrm{kg}-\mathrm{m}^{2}\right) \\
\end{array}$ & $\begin{array}{c}\text { Axial Inertia } \\
\left(\mathrm{kg}-\mathrm{m}^{2}\right)\end{array}$ \\
\hline \multirow[t]{2}{*}{0.1} & NTO & 19.72 & 2.47 & 2.00 & 0.0279 & 0.6340 & 42.01 & 0.17 & \begin{tabular}{|l}
-0.43 \\
\end{tabular} & 0.1082 & 0.0151 & 101.10 & -0.56 & 8.36 & 14.66 \\
\hline & & $22.24 \%$ & $11.09 \%$ & $0.00 \%$ & $6.05 \%$ & $2.88 \%$ & $99.40 \%$ & $0.00 \%$ & $0.00 \%$ & $0.02 \%$ & $0.93 \%$ & $36.96 \%$ & $12.88 \%$ & $44.26 \%$ & $0.00 \%$ \\
\hline \multirow[t]{2}{*}{0.2} & NTO & 39.90 & 2.20 & 1.70 & 0.0286 & 0.6490 & 80.25 & 0.17 & -0.35 & 0.1033 & 0.0122 & 205.55 & -0.47 & 22.42 & 38.64 \\
\hline & & $51.31 \%$ & $22.91 \%$ & $40.00 \%$ & $13.86 \%$ & $7.86 \%$ & $0.83 \%$ & $0.00 \%$ & $5.71 \%$ & $0.04 \%$ & $8.77 \%$ & $9.64 \%$ & $15.02 \%$ & $31.45 \%$ & $0.00 \%$ \\
\hline \multirow[t]{2}{*}{0.3} & NTO & 11.70 & 2.32 & 1.63 & 0.0271 & 0.3130 & 102.08 & 0.17 & -0.28 & 0.1002 & 0.0086 & 374.72 & -0.41 & 39.42 & 67.19 \\
\hline & & $478.82 \%$ & $28.79 \%$ & $20.39 \%$ & $18.51 \%$ & $59.75 \%$ & $3.03 \%$ & $0.00 \%$ & $3.57 \%$ & $0.01 \%$ & $9.95 \%$ & $15.77 \%$ & $4.43 \%$ & $1.24 \%$ & $0.00 \%$ \\
\hline \multirow[t]{2}{*}{0.4} & NTO & 32.57 & 1.54 & 0.90 & 0.0322 & 0.2500 & 117.24 & 0.17 & -0.23 & 0.0977 & 0.0070 & 501.52 & -0.34 & 59.26 & 97.65 \\
\hline & & $14.03 \%$ & $6.99 \%$ & $27.78 \%$ & $3.33 \%$ & $11.75 \%$ & 0.2222 & $0.00 \%$ & $1.74 \%$ & $0.01 \%$ & $85.71 \%$ & $6.11 \%$ & $3.53 \%$ & $3.76 \%$ & $0.00 \%$ \\
\hline \multirow[t]{2}{*}{0.5} & NTO & 49.99 & 1.44 & 0.75 & 0.0322 & 0.2077 & 133.94 & 0.16 & -0.17 & 0.0955 & 0.0069 & 630.27 & -0.29 & 77.52 & 127.83 \\
\hline & & $1.14 \%$ & $0.00 \%$ & $27.52 \%$ & $0.03 \%$ & $2.61 \%$ & $8.21 \%$ & $0.00 \%$ & $5.88 \%$ & $0.02 \%$ & $44.09 \%$ & $1.83 \%$ & $4.81 \%$ & $7.66 \%$ & $0.00 \%$ \\
\hline \multirow[t]{2}{*}{0.6} & NTO & 88.51 & 1.22 & 0.60 & 0.0341 & 0.2032 & 136.68 & 0.16 & -0.09 & 0.0936 & 0.0083 & 751.79 & -0.23 & 102.27 & 160.30 \\
\hline & & $17.79 \%$ & $0.16 \%$ & $1.67 \%$ & $10.50 \%$ & $11.59 \%$ & $2.13 \%$ & $0.00 \%$ & $11.11 \%$ & $0.01 \%$ & $10.12 \%$ & $1.71 \%$ & $2.62 \%$ & $2.71 \%$ & $0.00 \%$ \\
\hline \multirow[t]{2}{*}{0.7} & NTO & 121.05 & 1.03 & 0.50 & 0.0361 & 0.1985 & \begin{tabular}{|l|}
105.77 \\
\end{tabular} & 0.15 & -0.03 & 0.0941 & 0.0275 & 912.99 & -0.18 & 133.15 & 191.16 \\
\hline & & $31.72 \%$ & $1.46 \%$ & $7.60 \%$ & $0.72 \%$ & $19.82 \%$ & \begin{tabular}{|l|}
$1.49 \%$ \\
\end{tabular} & $0.00 \%$ & $0.00 \%$ & $0.07 \%$ & $6.62 \%$ & $4.38 \%$ & $8.79 \%$ & $4.30 \%$ & $0.00 \%$ \\
\hline \multirow[t]{2}{*}{0.8} & NTO & 156.31 & 0.60 & 0.23 & 0.0463 & 0.0800 & 39.73 & 0.12 & 0.02 & 0.1025 & 0.0083 & 1106.60 & -0.14 & 176.11 & 222.48 \\
\hline & & $8.48 \%$ & $0.00 \%$ & $8.70 \%$ & $0.06 \%$ & $14.18 \%$ & $91.87 \%$ & $360.98 \%$ & $150.00 \%$ & $53.41 \%$ & $100.00 \%$ & $2.10 \%$ & $0.00 \%$ & $0.28 \%$ & $0.00 \%$ \\
\hline \multirow[t]{2}{*}{0.1} & $\mathrm{MMH}$ & 13.18 & 2.34 & 1.90 & 0.0287 & 0.6417 & \begin{tabular}{|l|}
25.61 \\
\end{tabular} & 0.17 & -0.44 & 0.1078 & 0.0205 & 59.90 & -0.56 & 5.13 & 8.81 \\
\hline & & $16.54 \%$ & $11.05 \%$ & $5.26 \%$ & $5.12 \%$ & $3.96 \%$ & $0.35 \%$ & $0.00 \%$ & $0.00 \%$ & $0.02 \%$ & $0.00 \%$ & $3.49 \%$ & $5.88 \%$ & $2.53 \%$ & $0.00 \%$ \\
\hline \multirow[t]{2}{*}{0.2} & $\mathrm{MMH}$ & 25.80 & 2.13 & 1.50 & 0.0291 & 0.6855 & 45.74 & 0.17 & -0.36 & 0.1031 & 0.0143 & 125.86 & -0.44 & 12.93 & 23.41 \\
\hline & & $33.92 \%$ & $44.68 \%$ & $13.33 \%$ & $9.43 \%$ & $4.33 \%$ & $14.37 \%$ & $0.00 \%$ & $8.33 \%$ & $0.06 \%$ & $32.73 \%$ & $12.18 \%$ & $2.75 \%$ & $4.72 \%$ & $0.00 \%$ \\
\hline \multirow[t]{2}{*}{0.3} & $\mathrm{MMH}$ & 14.80 & 1.90 & 1.60 & 0.0299 & 0.3212 & 59.04 & 0.17 & -0.28 & 0.1001 & 0.0105 & 222.23 & -0.42 & 24.51 & 40.56 \\
\hline & & $162.06 \%$ & $5.73 \%$ & $12.50 \%$ & $3.01 \%$ & $96.60 \%$ & $3.40 \%$ & $0.00 \%$ & $5.36 \%$ & $0.02 \%$ & $9.81 \%$ & $11.70 \%$ & $0.24 \%$ & $0.90 \%$ & $0.00 \%$ \\
\hline \multirow[t]{2}{*}{0.4} & $\mathrm{MMH}$ & \begin{tabular}{|l|}
11.81 \\
\end{tabular} & 1.73 & 1.15 & 0.0304 & 0.2034 & 74.31 & 0.17 & -0.23 & 0.0976 & 0.0107 & 308.65 & -0.35 & 37.33 & 59.40 \\
\hline & & $67.19 \%$ & $10.08 \%$ & $21.74 \%$ & $5.43 \%$ & $27.86 \%$ & $15.00 \%$ & $0.60 \%$ & $2.22 \%$ & $0.03 \%$ & $34.33 \%$ & $1.04 \%$ & $2.85 \%$ & $3.32 \%$ & $0.00 \%$ \\
\hline \multirow[t]{2}{*}{0.5} & $\mathrm{MMH}$ & 32.92 & 1.41 & 0.80 & 0.0326 & 0.2126 & 82.86 & 0.16 & -0.02 & 0.0955 & 0.0118 & 377.73 & -0.29 & 49.70 & 78.20 \\
\hline & & $3.52 \%$ & $1.42 \%$ & $8.75 \%$ & $0.71 \%$ & $1.17 \%$ & $5.16 \%$ & $0.00 \%$ & $2.50 \%$ & $0.00 \%$ & $11.36 \%$ & $0.82 \%$ & $2.10 \%$ & $3.36 \%$ & $0.00 \%$ \\
\hline \multirow[t]{2}{*}{0.6} & $\mathrm{MMH}$ & 41.89 & 1.24 & 0.60 & 0.0338 & 0.1762 & 81.02 & 0.16 & -0.09 & 0.0934 & 0.0181 & 469.23 & -0.24 & 63.18 & 97.01 \\
\hline & & $24.68 \%$ & $0.24 \%$ & $8.33 \%$ & $0.12 \%$ & $15.00 \%$ & $9.45 \%$ & $0.10 \%$ & $8.70 \%$ & $0.05 \%$ & $53.04 \%$ & $0.57 \%$ & $1.67 \%$ & $0.60 \%$ & $0.00 \%$ \\
\hline \multirow[t]{2}{*}{0.7} & $\mathrm{MMH}$ & 55.41 & 1.04 & 0.48 & 0.0360 & 0.1692 & 62.73 & 0.15 & -0.03 & 0.0943 & 0.0283 & 572.70 & -0.19 & 82.00 & 115.95 \\
\hline & & $4.89 \%$ & $0.19 \%$ & $2.08 \%$ & $0.08 \%$ & $2.90 \%$ & $1.58 \%$ & $0.04 \%$ & $33.33 \%$ & $0.03 \%$ & $1.87 \%$ & $0.65 \%$ & $1.87 \%$ & $0.80 \%$ & $0.00 \%$ \\
\hline \multirow[t]{2}{*}{0.8} & $\mathrm{MMH}$ & 146.90 & 0.60 & 0.25 & 0.0466 & 0.1222 & 44.73 & 0.12 & 0.02 & 0.1020 & 0.0308 & 597.87 & -0.13 & 106.17 & 134.91 \\
\hline & & $19.38 \%$ & $1.68 \%$ & $2.36 \%$ & $0.88 \%$ & $18.13 \%$ & $47.05 \%$ & $0.81 \%$ & $50.00 \%$ & $0.18 \%$ & $73.06 \%$ & $8.28 \%$ & $5.30 \%$ & $0.97 \%$ & $0.00 \%$ \\
\hline
\end{tabular}




\section{Data Trends}

After the pendulum parameters were found, trends in the parameters between fill fractions were needed. Trends allow for easier testing of the attitude control models and for fewer total CFD models to be run, as a case is not needed for every possible fill fraction.

Because the process of finding an equivalent mechanical model was completed twice, there were two parameter sets at each fill fraction. While a better trend may have been obtained by choosing a different set for each parameter at a single fill fraction, it was determined that doing so would introduce more error into the trends because each set was optimized as a whole. To choose the parameter set for each case, all parameters of interest were plotted for both sets. At each fill fraction for each parameter, the set which resulted in a better overall fit was recorded. After this process was completed for each parameter, the set which improved the fit for the most parameters was chosen to represent that fill fraction.

The trend found for pendulum masses is shown in Figure 10. The mass of the pendulum modeling the sector slosh increased approximately linearly until reaching a fill fraction of 0.6 when it began to decrease. This is likely because the fluid has nearly reached the top of the PMD at that point. The mass representing the full tank slosh has a discontinuity between fill fractions 0.2 and 0.3 likely caused by the transition of the tank geometry from hemispherical to cylindrical and a greater separation between the PMD and the walls of the tank. The mass of the full tank slosh then increases as fill fraction increases.

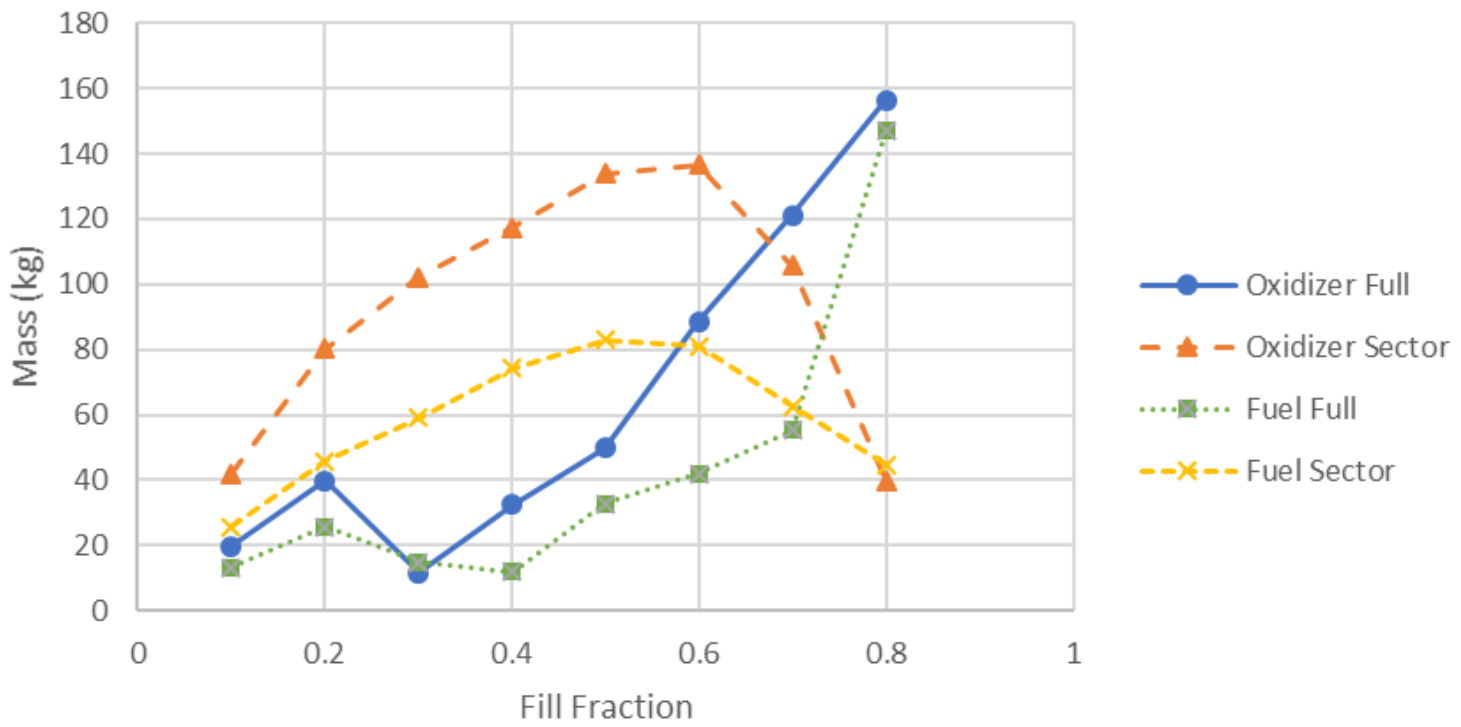

Fig. 10 Pendulum mass trend for high acceleration.

The trend found for pendulum hinge height is shown in Figure 11. It was found that there is an inverse correlation between hinge height and fill fraction for the full tank slosh and a positive correlation for the sector slosh. There appears to be no transitions in this data as there were for pendulum masses.

The static mass location linearly increases through all fill fractions analyzed as shown in Figure 12. The static mass location is also nearly the same for both the oxidizer and the fuel. 


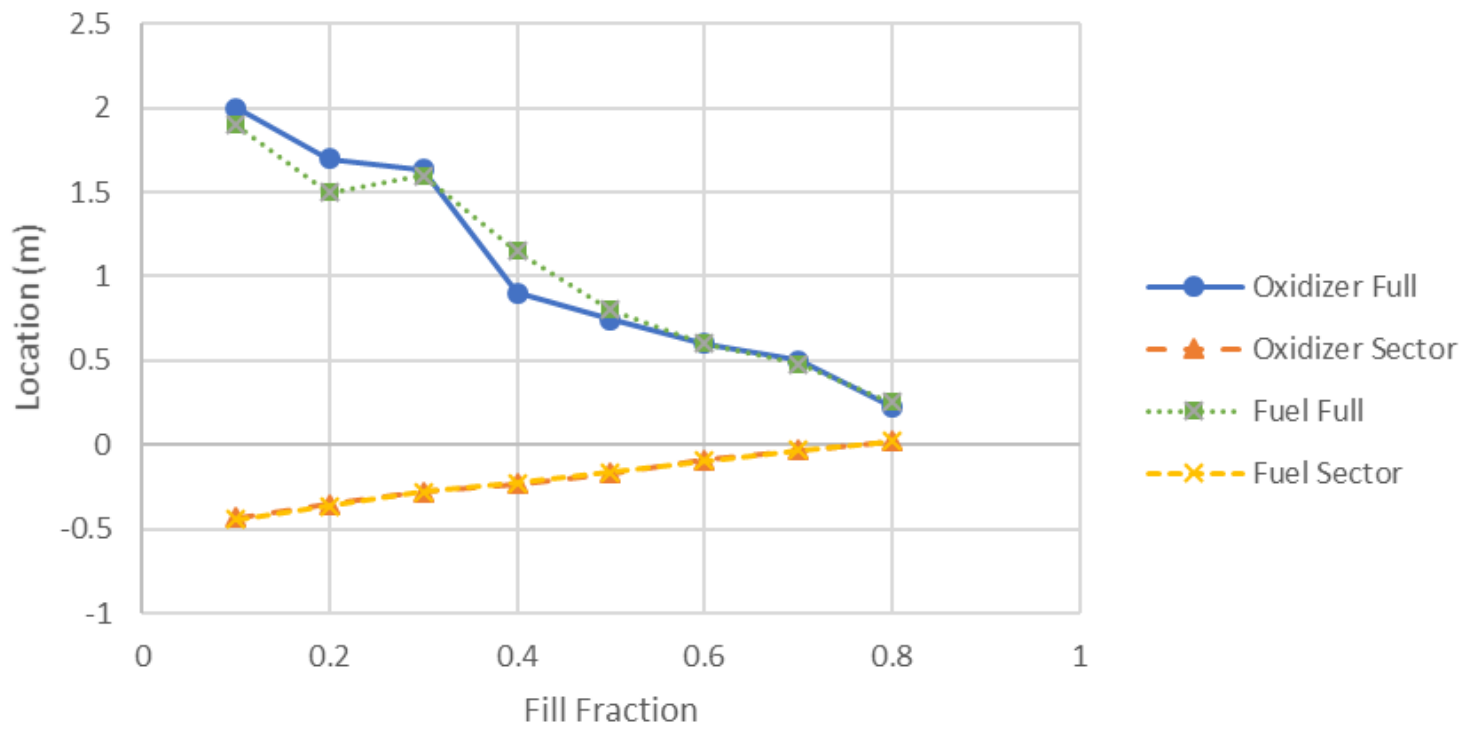

Fig. 11 Pendulum hinge height trend for high acceleration.

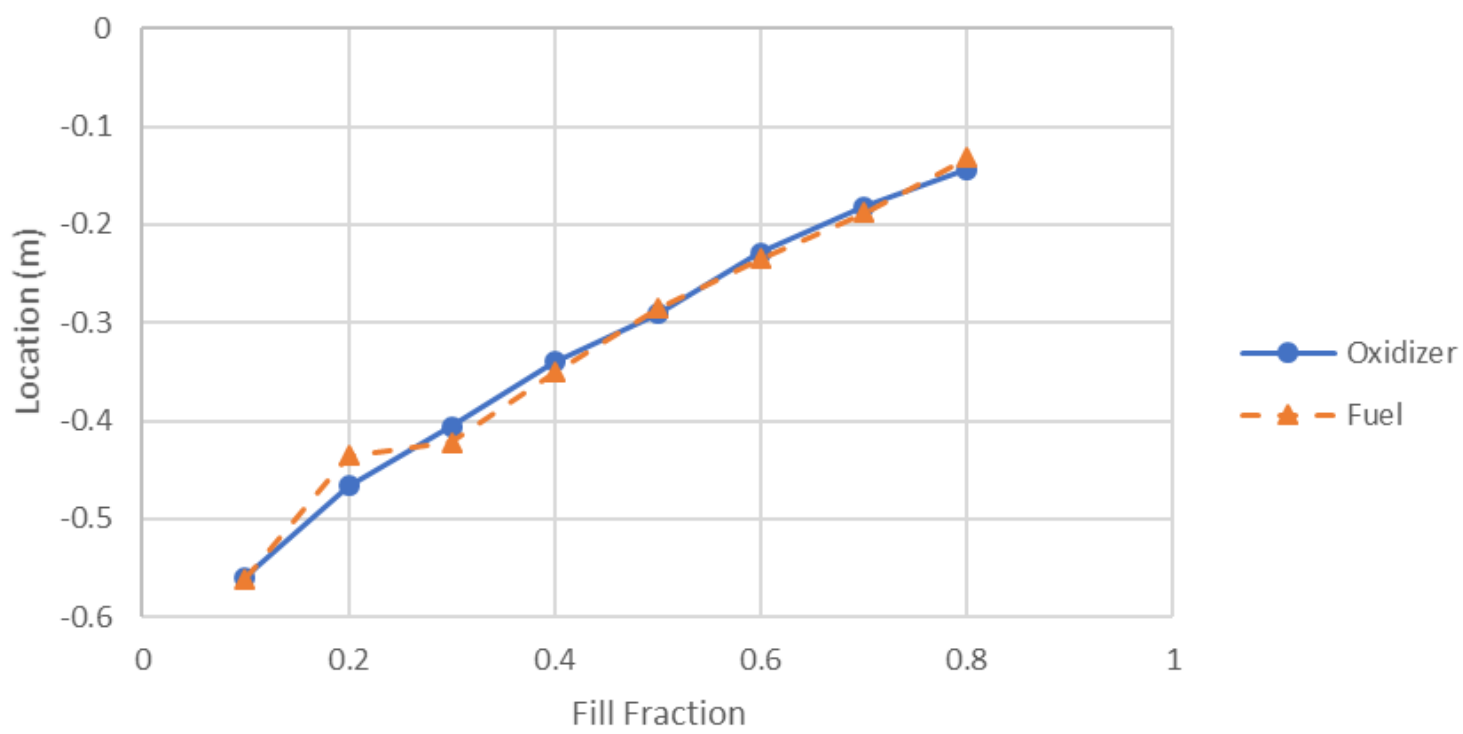

Fig. 12 Static mass location trend for high acceleration.

In each slosh mode, the frequency of the oxidizer and fuel slosh are approximately the same as shown in Figure 13. The frequency of the sector slosh decreases linearly until a fill fraction between 0.6 and 0.7 when is begins to increase. The frequency of the full tank slosh increases linearly until approximately the same fill fraction where it continues to increase but with a higher slope. The transition, again, is likely due to the propellant beginning to slosh over the top of the PMD. 


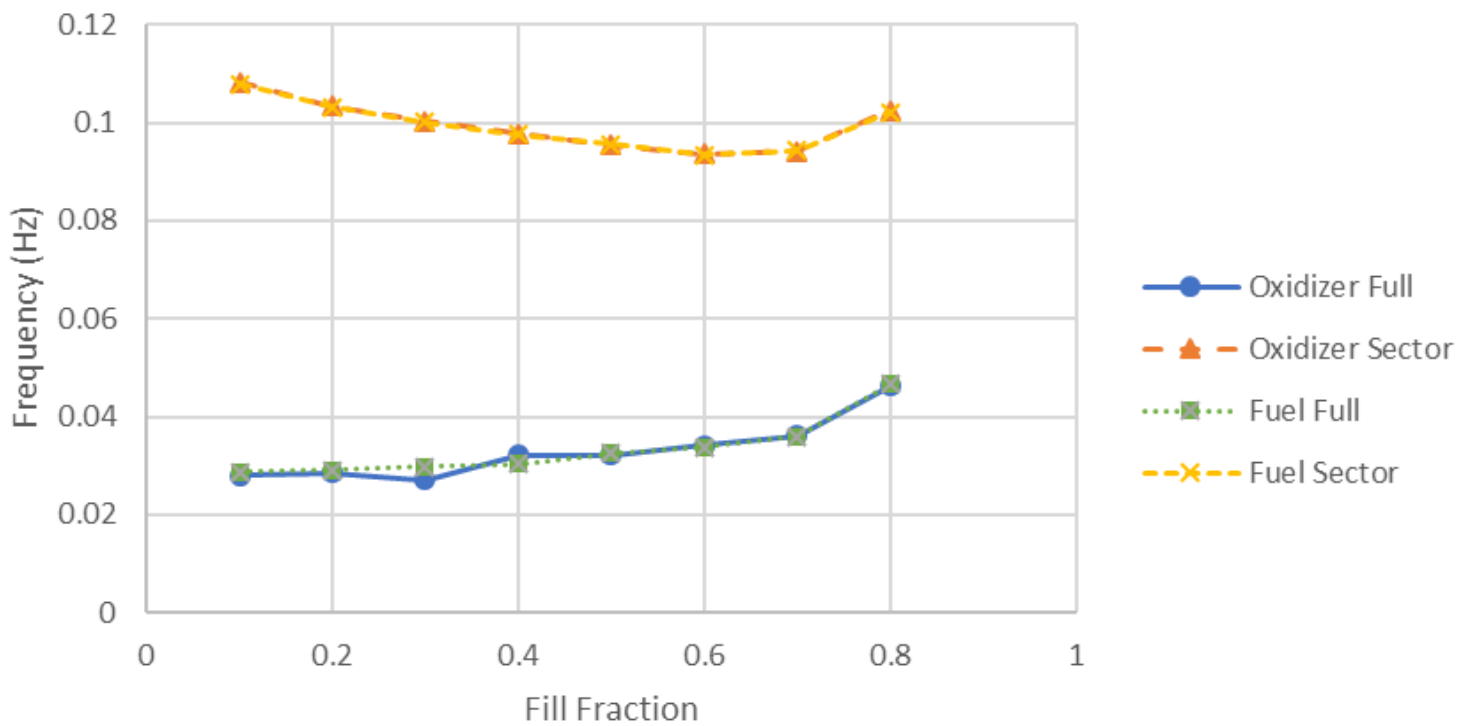

Fig. 13 Pendulum frequency trend for high acceleration.

In general, the damping ratio of the full tank slosh pendulum decreases while the damping ratio for the sector slosh pendulum remains approximately the same as shown in Figure 14. However, there is one point around a fill fration of 0.2 where the damping constant of the full tank slosh increases. This could be due to the geometry transition as noted in previous trends.

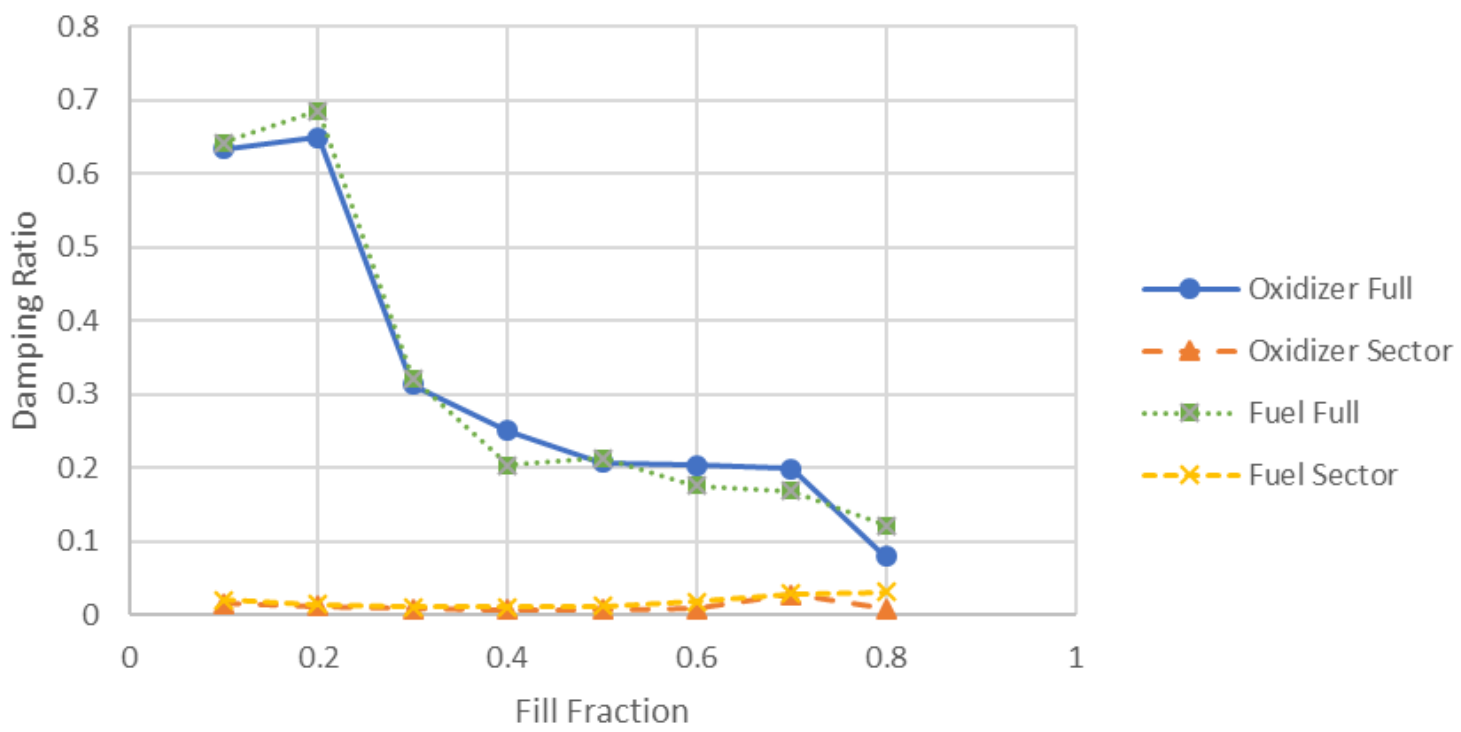

Fig. 14 Pendulum damping ratio trend for high acceleration. 


\section{Low G Cases}

\section{A. Surface Evolver}

Surface Evolver was used to model both the oxidizer and fuel at the lateral accelerations and fill fractions shown in Table 3 and Table 4 . The contact angle between the propellants and the tank surface is 0 degrees.

Table 3 Oxidizer lateral accelerations.

\begin{tabular}{|c|c|c|c|c|c|}
\hline \multicolumn{6}{|c|}{ Oxidizer } \\
\hline $\begin{array}{c}\text { Mass Fill Fraction } \\
\text { of 1628.3 kg }\end{array}$ & Temp, Deg C & $\begin{array}{c}\text { Acceleration 1 } \\
\mathrm{m} / \mathrm{s}^{2}\end{array}$ & $\begin{array}{c}\text { Acceleration 2 } \\
\mathrm{m} / \mathrm{s}^{2}\end{array}$ & $\begin{array}{c}\text { Acceleration 3 } \\
\mathrm{m} / \mathrm{s}^{2}\end{array}$ & $\begin{array}{c}\text { Acceleration } 4 \\
\mathrm{~m} / \mathrm{s}^{2}\end{array}$ \\
\hline 0.1 & 27 & 0 & $2.77 \mathrm{e}-5$ & $8.64 \mathrm{e}-5$ & $11.08 \mathrm{e}-5$ \\
\hline 0.2 & 27 & 0 & $2.77 \mathrm{e}-5$ & $5.54 \mathrm{e}-5$ & $11.08 \mathrm{e}-5$ \\
\hline 0.3 & 0 & 0 & $2.50 \mathrm{e}-5$ & $5.00 \mathrm{e}-5$ & $10.00 \mathrm{e}-5$ \\
\hline 0.3 & 27 & 0 & $2.77 \mathrm{e}-5$ & $5.54 \mathrm{e}-5$ & $11.08 \mathrm{e}-5$ \\
\hline 0.4 & 27 & 0 & $2.77 \mathrm{e}-5$ & $5.54 \mathrm{e}-5$ & $11.08 \mathrm{e}-5$ \\
\hline 0.5 & 27 & 0 & $2.77 \mathrm{e}-5$ & $5.54 \mathrm{e}-5$ & $11.08 \mathrm{e}-5$ \\
\hline 0.6 & 15 & 0 & $2.50 \mathrm{e}-5$ & $5.00 \mathrm{e}-5$ & $10.00 \mathrm{e}-5$ \\
\hline 0.7 & 15 & 0 & $2.50 \mathrm{e}-5$ & $5.00 \mathrm{e}-5$ & $10.00 \mathrm{e}-5$ \\
\hline 0.8 & 15 & 0 & $2.50 \mathrm{e}-5$ & $5.00 \mathrm{e}-5$ & $10.00 \mathrm{e}-5$ \\
\hline
\end{tabular}

Table 4 Fuel lateral accelerations.

\begin{tabular}{|c|c|c|c|c|c|}
\hline \multicolumn{6}{|c|}{ Fuel } \\
\hline $\begin{array}{c}\text { Mass Fill Fraction } \\
\text { of 986.9 kg }\end{array}$ & Temp, Deg C & $\begin{array}{c}\text { Acceleration 1 } \\
\mathrm{m} / \mathrm{s}^{2}\end{array}$ & $\begin{array}{c}\text { Acceleration 2 } \\
\mathrm{m} / \mathrm{s}^{2}\end{array}$ & $\begin{array}{c}\text { Acceleration 3 } \\
\mathrm{m} / \mathrm{s}^{2}\end{array}$ & $\begin{array}{c}\text { Acceleration } 4 \\
\mathrm{~m} / \mathrm{s}^{2}\end{array}$ \\
\hline 0.1 & 27 & 0 & $2.50 \mathrm{e}-5$ & $5.00 \mathrm{e}-5$ & $10.00 \mathrm{e}-5$ \\
\hline 0.2 & 27 & 0 & $2.50 \mathrm{e}-5$ & $5.00 \mathrm{e}-5$ & $10.00 \mathrm{e}-5$ \\
\hline 0.3 & 27 & 0 & $2.50 \mathrm{e}-5$ & $5.00 \mathrm{e}-5$ & $10.00 \mathrm{e}-5$ \\
\hline 0.4 & 27 & 0 & $2.50 \mathrm{e}-5$ & $5.00 \mathrm{e}-5$ & $10.00 \mathrm{e}-5$ \\
\hline 0.5 & 27 & 0 & $2.50 \mathrm{e}-5$ & $5.00 \mathrm{e}-5$ & $10.00 \mathrm{e}-5$ \\
\hline 0.6 & 15 & 0 & $2.50 \mathrm{e}-5$ & $5.00 \mathrm{e}-5$ & $10.00 \mathrm{e}-5$ \\
\hline 0.7 & 15 & 0 & $2.50 \mathrm{e}-5$ & $5.00 \mathrm{e}-5$ & $10.00 \mathrm{e}-5$ \\
\hline 0.8 & 15 & 0 & $2.50 \mathrm{e}-5$ & $5.00 \mathrm{e}-5$ & $10.00 \mathrm{e}-5$ \\
\hline
\end{tabular}

The model was initialized with the propellant centered about the centerline of the tank. The model was iterated until no movement in the center of mass could be observed, or until the movement was very small. Once a steadystate solution was achieved, the center of masses and moments of inertia were recorded and a snapshot of the graphical output was taken. The lateral acceleration was then increased and the process repeated until all the solutions for the desired lateral accelerations were obtained. The graphical outputs for oxidizer are shown in Figure 15 and 16. The fuel graphical output is similar, with less bubble movement due to the fuel's higher surface tension and lower density. The Surface Evolver model has facets around the gas bubble, with the propellant being in the open space below the gas bubble. 

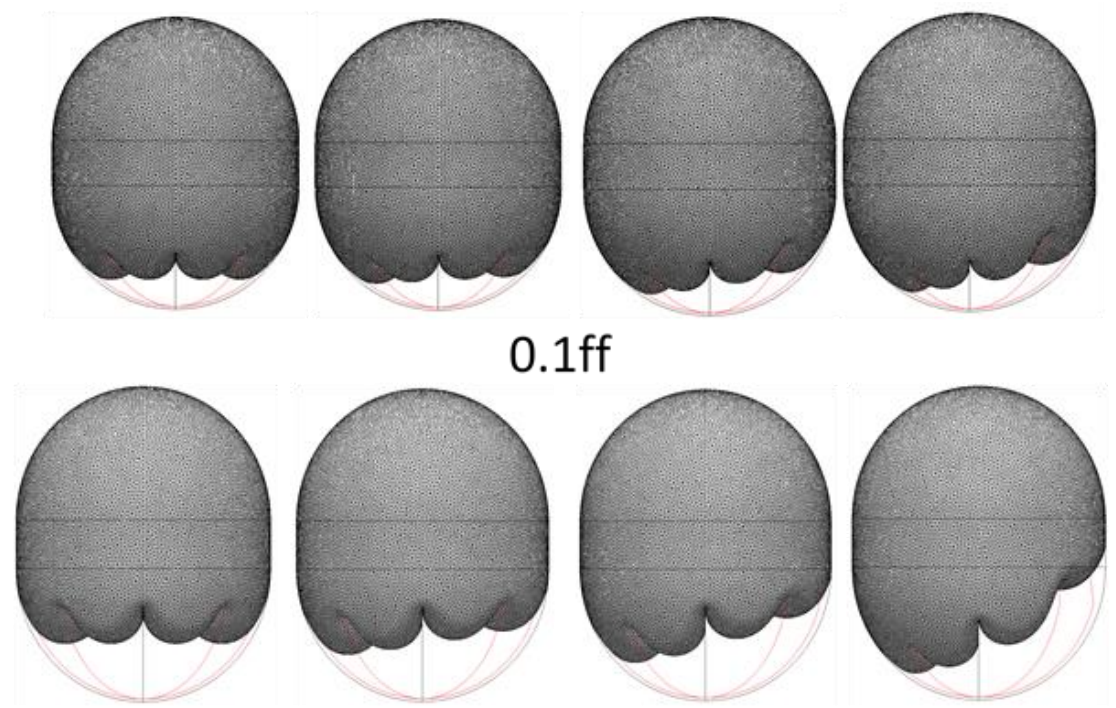

\section{$0.2 \mathrm{ff}$}

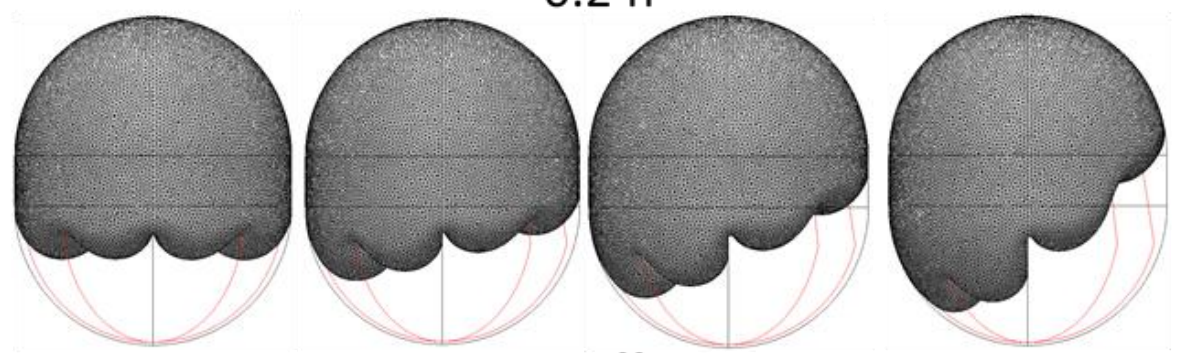

$0.3 \mathrm{ff}$

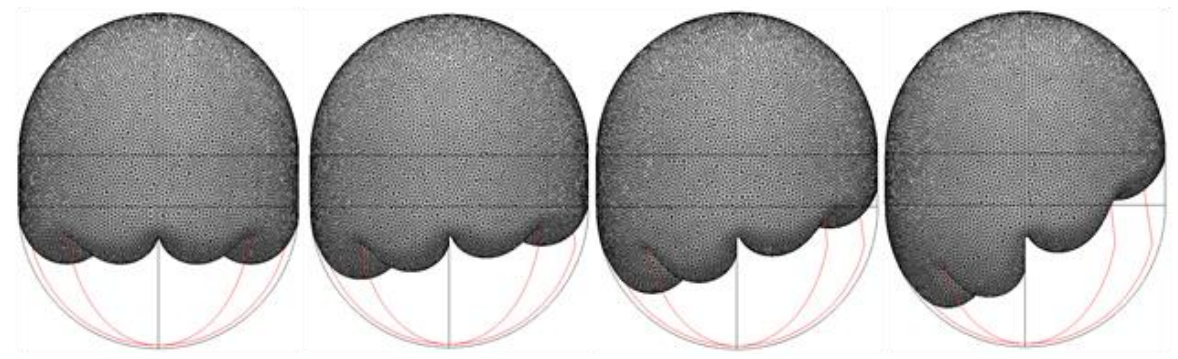

\section{$0.3 \mathrm{ff}$, Temp $=0 \mathrm{deg} C$}
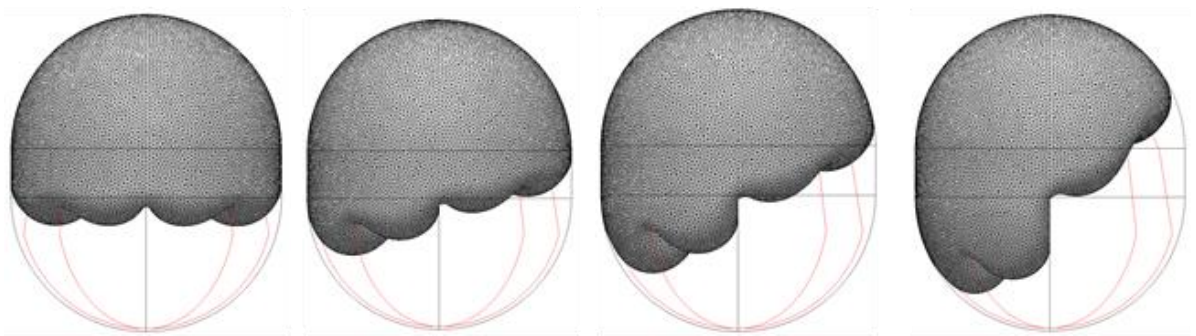

\section{$0.4 \mathrm{ff}$}

Fig. 15 Graphical results for fill fractions 0.1 through 0.4 of NTO at lateral accelerations shown in

Table 3. 

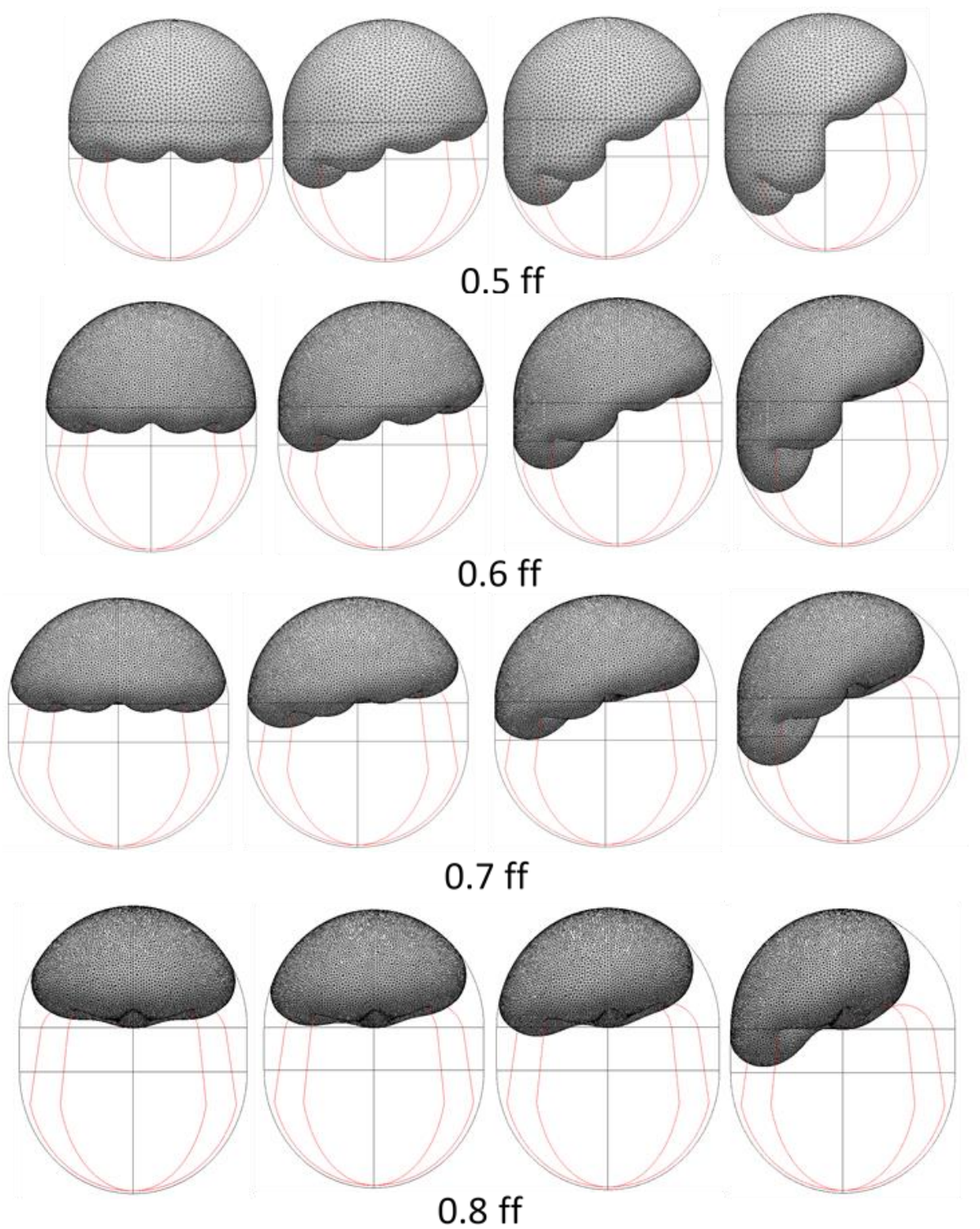

Fig. 16 Graphical results for fill fractions 0.5 through 0.8 of NTO at lateral accelerations shown in

Table 3.

This approach is taken because it is easier to model a 0-degree contact angle by modeling the gas bubble. The propellant center of mass and the propellant moments of inertia can be calculated implicitly either within Surface Evolver or with codes outside of Surface Evolver from the gas bubble.

A plot of the center of mass offset from the centerline in the horizontal direction is shown in Figure 17. The low, medium, and high accelerations listed in the figure are listed as accelerations 2, 3, and 4 respectively from Tables 3 and 4 . The fuel has a lower density and a higher surface tension and so the fuel center of mass does not move the same distance as the oxidizer center of mass when both are under the same lateral acceleration. 


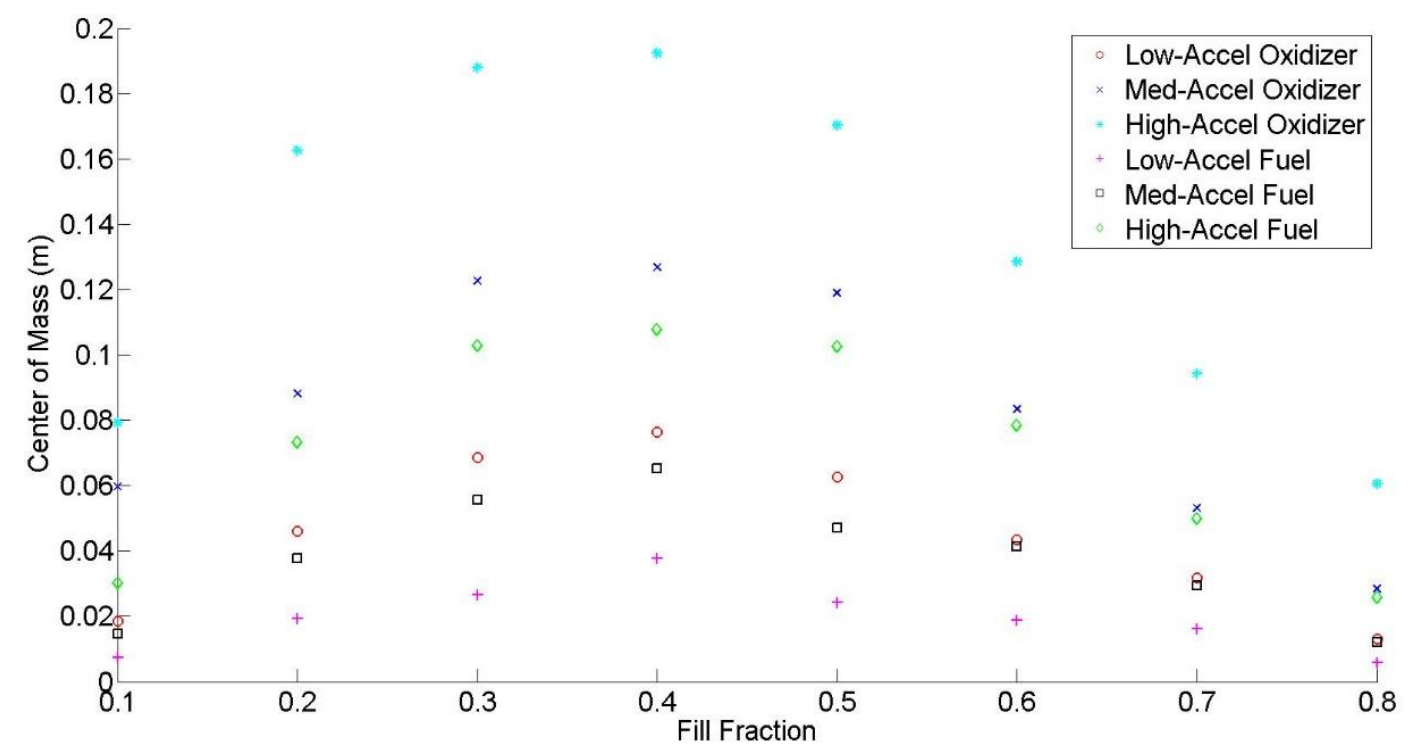

Fig. 17 Center of mass movement as a function of fill fraction and acceleration.

\section{B. Pendulum Parameters}

The mechanical model for low $\mathrm{g}$ slosh consists of a single pendulum with a torsional spring and a static mass as shown in Figure 18. The spring constant is dependent on the fill fraction.

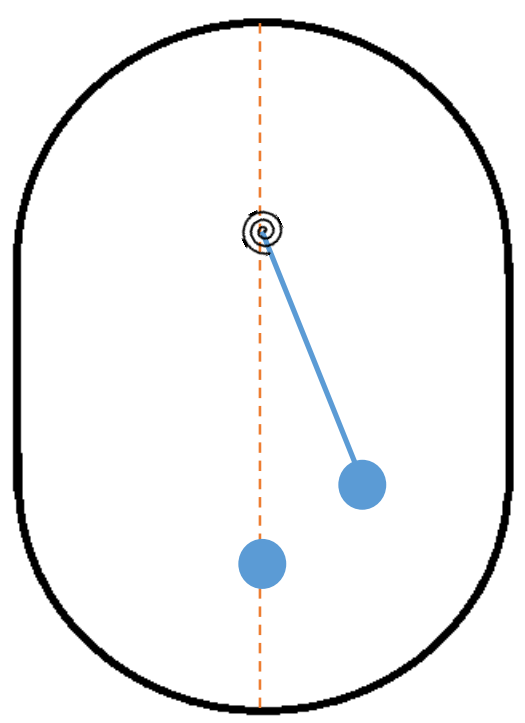

Fig. 18 Diagram of mechanical system used to model slosh under low accelerations. Single pendulum with torsional spring and a static mass.

Surface Evolver minimizes the energy in the problem, which is a balance between the increased surface energy introduced as the propellant is pushed to the side of the tank and the reduced potential energy as the propellant center of mass moves in the direction of acceleration. At the lower and higher fill fractions, a small center of mass movement results in a large surface energy increase relative to the mid-level fill fractions.

The method outlined in Ref. [2] is used to derive the pendulum and spring parameters. The angle of the liquid-gas interface from horizontal is varied to provide the best fit for the data. Figure 19-20 shows how well the pendulum and 
spring model matches the Surface Evolver data for NTO. Again, MMH shows similar results to NTO with slight variations due to a difference in density. A moment of inertia is added to the static moment of inertia so that the settled propellant and the settled pendulum and spring model have the same moment of inertia. The pendulum/spring model parameters are shown in Table 5. The damping ratio was assumed to be $10 \%$ from heritage analyses [2].

Table 5 Pendulum/spring model parameters.

\begin{tabular}{|c|c|c|c|c|c|c|c|c|c|c|c|c|c|}
\hline \multirow{2}{*}{\multicolumn{4}{|c|}{ Cases }} & \multirow{2}{*}{\multicolumn{6}{|c|}{ Pendulum for Full-Tank Mode }} & \multirow{2}{*}{\multicolumn{4}{|c|}{ Static Mass }} \\
\hline & & & & & & & & & & & & & \\
\hline $\begin{array}{c}\text { Mass Fill } \\
\text { Frac }\end{array}$ & $\begin{array}{c}\text { Prop Mass, } \\
\text { kg }\end{array}$ & Temp, & Propellant & Mass, kg & Length, $\mathrm{m}$ & $\begin{array}{l}\text { Hinge } \\
\text { Point, } m\end{array}$ & $\begin{array}{c}\text { Frequency, } \\
\mathrm{Hz}\end{array}$ & $\begin{array}{c}\text { *Damping } \\
\text { Ratio, \% }\end{array}$ & $\begin{array}{c}\text { Spring } \\
\text { Constant, N- } \\
\mathrm{m} / \mathrm{rad}\end{array}$ & Mass, kg & $\begin{array}{l}\text { Hinge } \\
\text { Point, } \mathrm{m}\end{array}$ & $\begin{array}{c}\text { Moment of } \\
\begin{array}{c}\text { Inertia } \\
\text { about } \\
\text { Horizontal } \\
\text { Axis, kg-m }\end{array} \\
\end{array}$ & $\begin{array}{c}\text { Moment of } \\
\text { Inertia } \\
\text { about } \\
\text { Vertical } \\
\text { Axis, kg-m }\end{array}$ \\
\hline 0.1 & 162.8 & 27 & Oxidizer & 108 & 0.59 & -0.04 & 0.0050 & 10 & 0.038 & 54 & -0.14 & 2 & 8 \\
\hline 0.2 & 325.7 & 27 & Oxidizer & 285 & 0.40 & -0.09 & 0.0036 & 10 & 0.024 & 41 & -0.11 & 18 & 29 \\
\hline 0.3 & 488.5 & 0 & Oxidizer & 362 & 0.38 & -0.12 & 0.0030 & 10 & 0.018 & 126 & -0.14 & 27 & 55 \\
\hline 0.3 & 488.5 & 27 & Oxidizer & 365 & 0.39 & -0.10 & 0.0027 & 10 & 0.016 & 124 & -0.13 & 29 & 56 \\
\hline 0.4 & 651.3 & 27 & Oxidizer & 563 & 0.28 & -0.05 & 0.0028 & 10 & 0.014 & 88 & -0.52 & 58 & 88 \\
\hline 0.5 & 814.2 & 27 & Oxidizer & 592 & 0.29 & -0.04 & 0.0026 & 10 & 0.013 & 222 & -0.25 & 85 & 123 \\
\hline 0.6 & 977 & 15 & Oxidizer & 657 & 0.26 & -0.01 & 0.0029 & 10 & 0.015 & 320 & -0.26 & 114 & 157 \\
\hline 0.7 & 1139.8 & 15 & Oxidizer & 702 & 0.23 & 0.05 & 0.0036 & 10 & 0.020 & 437 & -0.28 & 146 & 194 \\
\hline 0.8 & 1302.6 & 15 & Oxidizer & 515 & 0.26 & 0.10 & 0.0041 & 10 & 0.023 & 788 & -0.17 & 191 & 233 \\
\hline 0.1 & 98.7 & 27 & Fuel & 66 & 0.60 & 0.00 & 0.0076 & 10 & 0.054 & 33 & -0.20 & 3 & 5 \\
\hline 0.2 & 197.4 & 27 & Fuel & 120 & 0.55 & -0.11 & 0.0045 & 10 & 0.029 & 78 & -0.10 & 0 & 17 \\
\hline 0.3 & 296.1 & 27 & Fuel & 254 & 0.34 & -0.11 & 0.0044 & 10 & 0.022 & 42 & -0.10 & 20 & 34 \\
\hline 0.4 & 394.8 & 27 & Fuel & 291 & 0.33 & -0.10 & 0.0037 & 10 & 0.017 & 104 & -0.15 & 31 & 54 \\
\hline 0.5 & 493.5 & 27 & Fuel & 339 & 0.29 & -0.05 & 0.0042 & 10 & 0.020 & 154 & -0.24 & 51 & 74 \\
\hline 0.6 & 592.1 & 15 & Fuel & 370 & 0.27 & 0.00 & 0.0043 & 10 & 0.020 & 222 & -0.26 & 69 & 95 \\
\hline 0.7 & 690.8 & 15 & Fuel & 371 & 0.26 & 0.05 & 0.0047 & 10 & 0.022 & 320 & -0.23 & 90 & 118 \\
\hline 0.8 & 789.5 & 15 & Fuel & 317 & 0.26 & 0.09 & 0.0065 & 10 & 0.036 & 472 & -0.17 & 116 & 141 \\
\hline
\end{tabular}

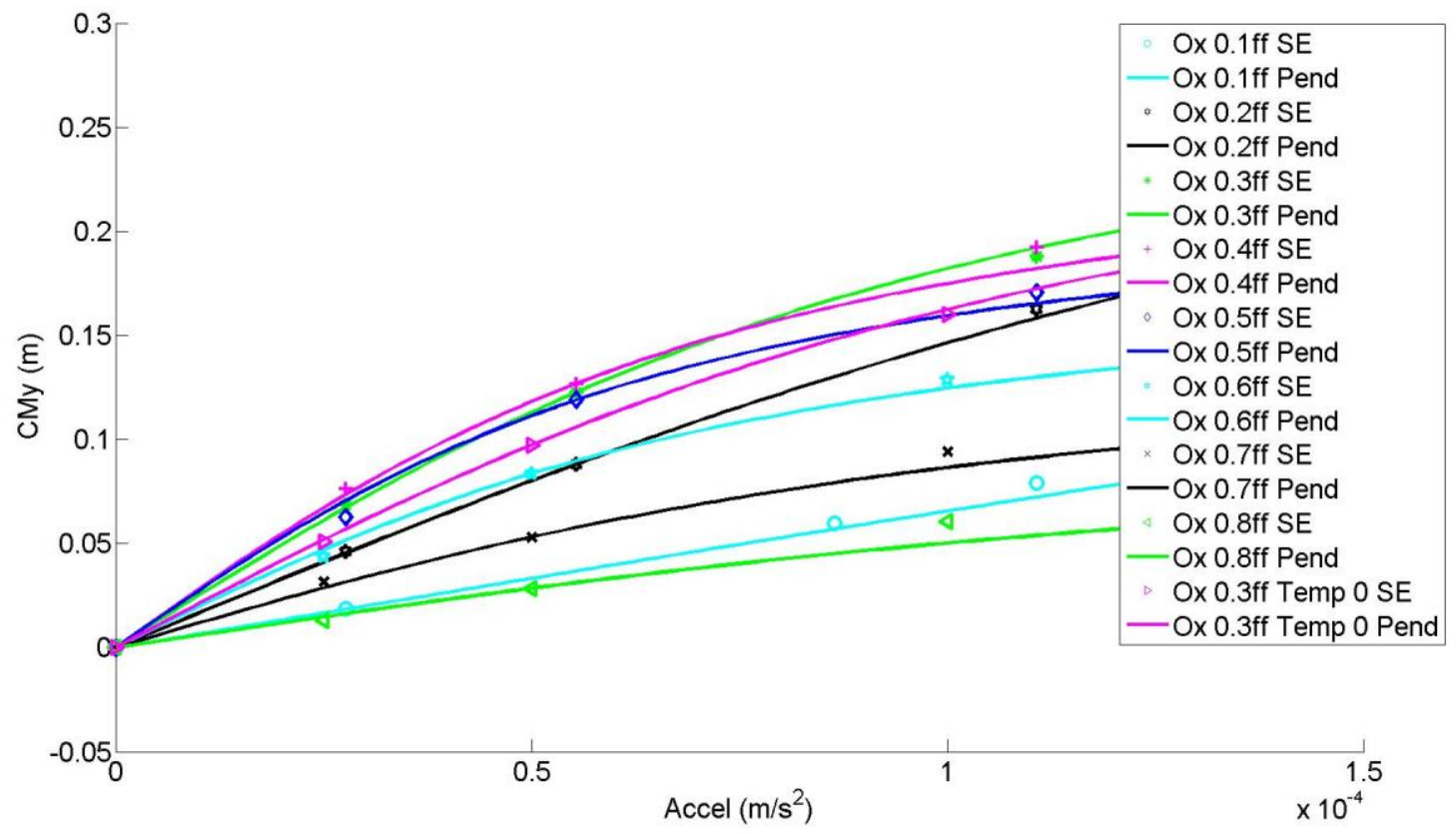

Fig. 19 Center of mass matching between Surface Evolver (SE) results and pendulum/spring (Pend) model results in the horizontal direction for NTO. 


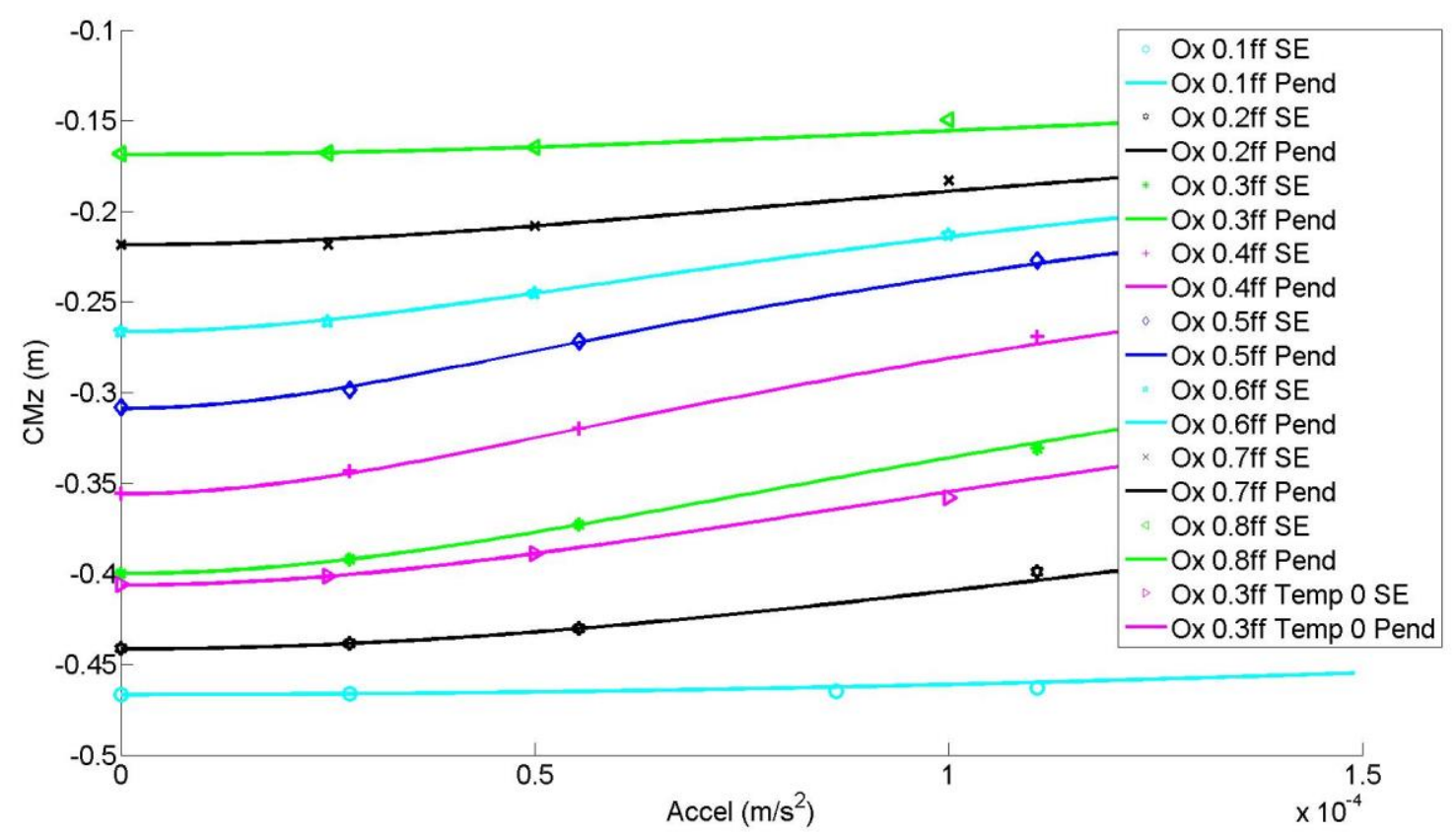

Fig. 20 Center of mass matching between Surface Evolver (SE) results and pendulum/spring (Pend) model results in the vertical direction for NTO.

\section{Uncertainty Between Users}

Because there is a fair amount of uncertainty associated with the method used to derive the low-g pendulum parameters, an attempt was made to understand the accuracy of the models. The partial derivatives of the equations used to derive the pendulum parameters were taken with respect to the input parameters and an uncertainty in the input variables was assumed. A root squared sum was used to add up the errors from the input variables to give an uncertainty for each parameter. Because the uncertainty depended on the input values, this approach had to be repeated for each case.

To check the assumptions made about the uncertainty of the input values, three different engineers used the same Surface Evolver results and the same derivation approach to derive the pendulum parameters. The pendulum parameters from the three engineers were plotted with an error bar placed on the values that were derived by User 2 . These are given in Figures 21-29. 


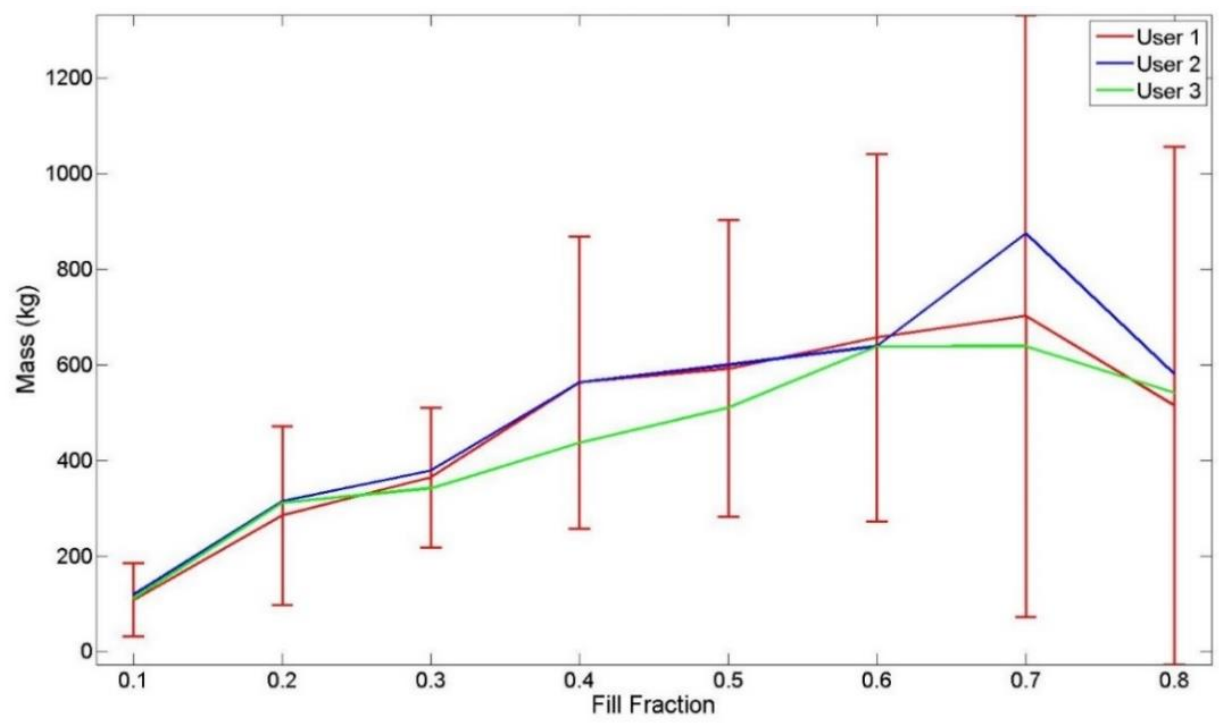

Fig. 212 Oxidizer pendulum mass vs fill fraction.

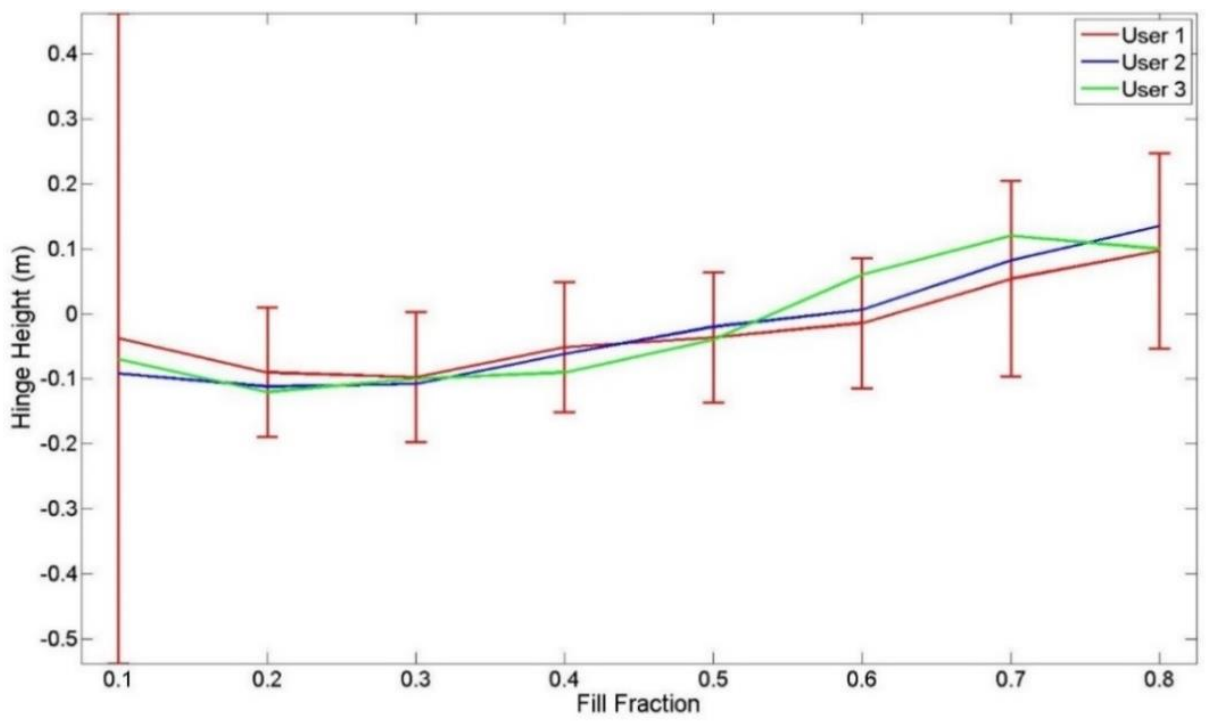

Fig. 22 Oxidizer pendulum hinge height vs fill fraction. 


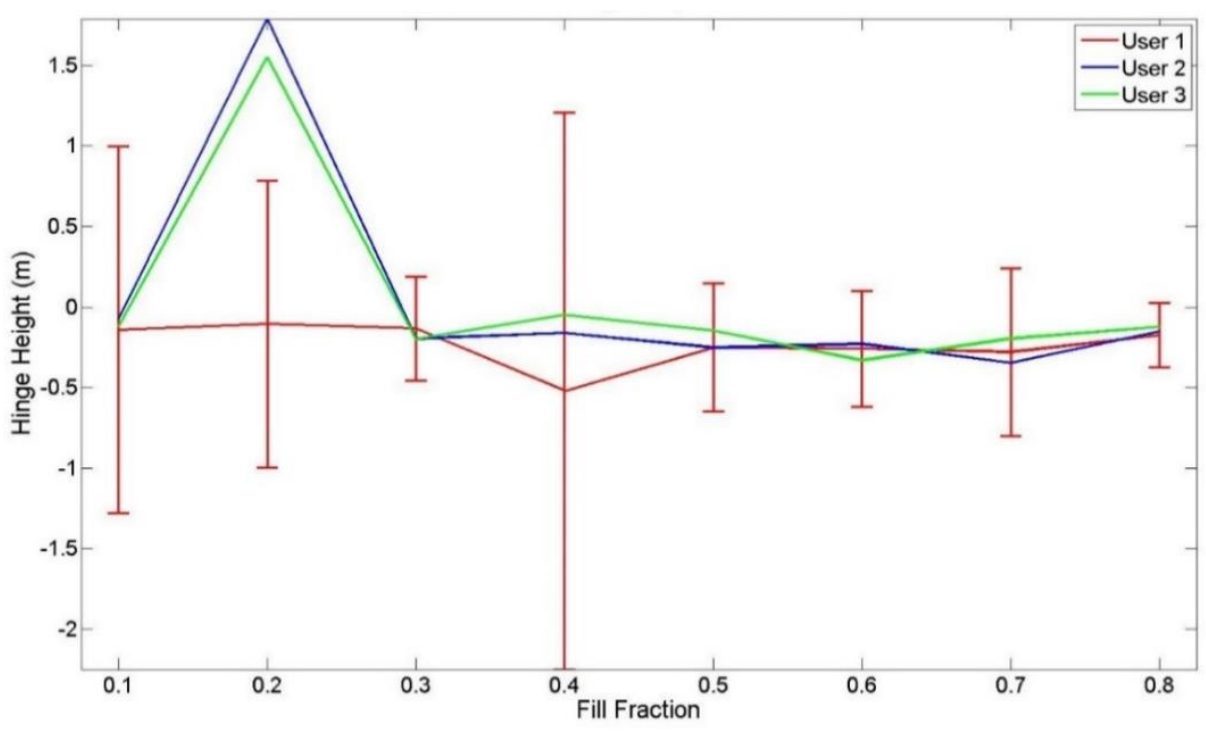

Fig. 23 Oxidizer static hinge height vs fill fraction.

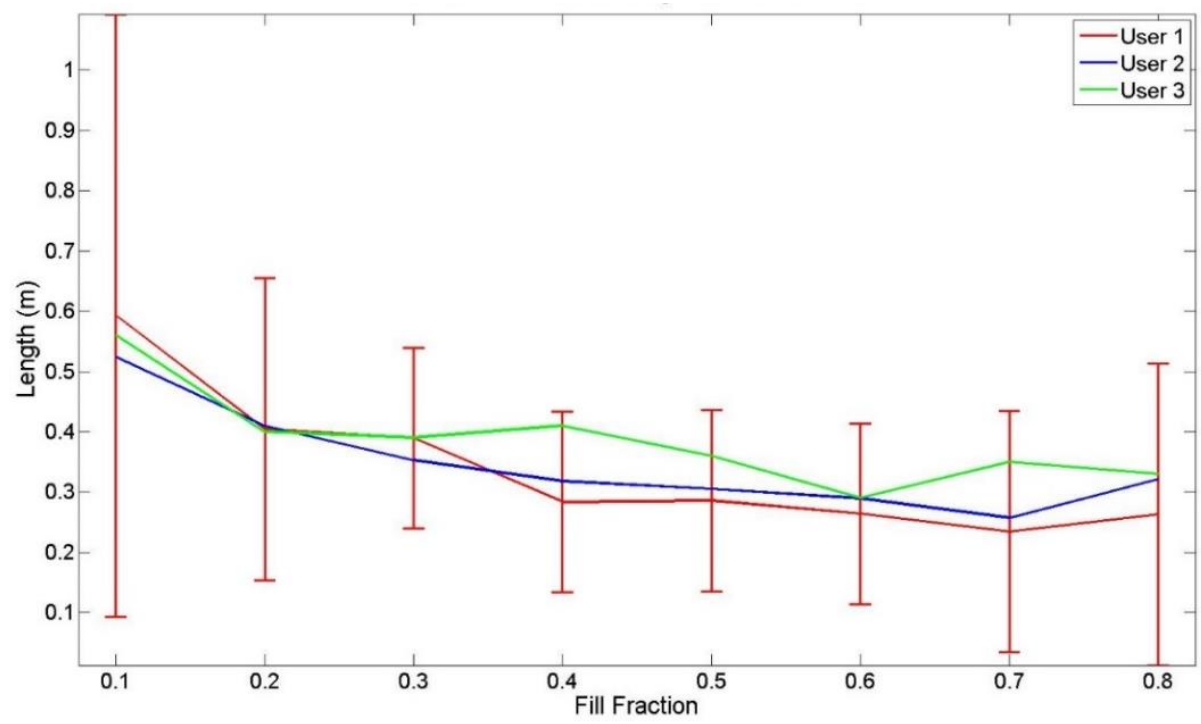

Fig. 24 Oxidizer pendulum length vs fill fraction. 


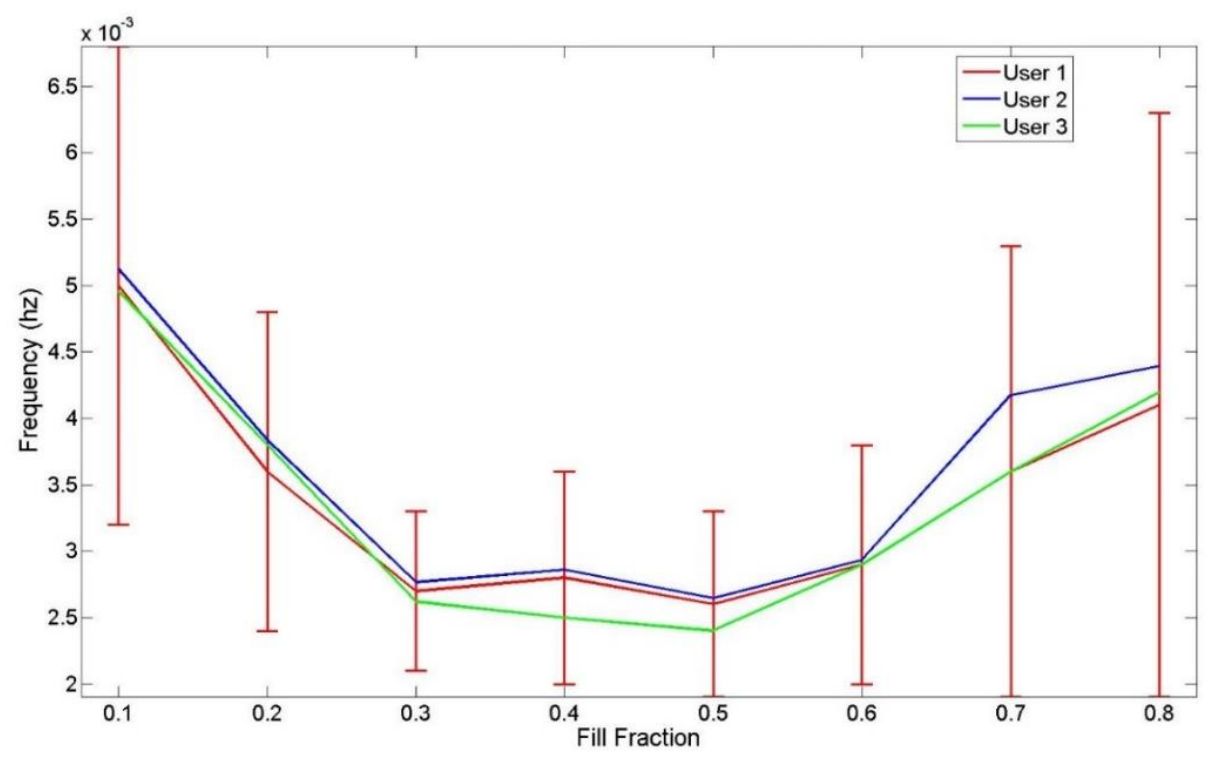

Fig. 25 Oxidizer frequency vs fill fraction.

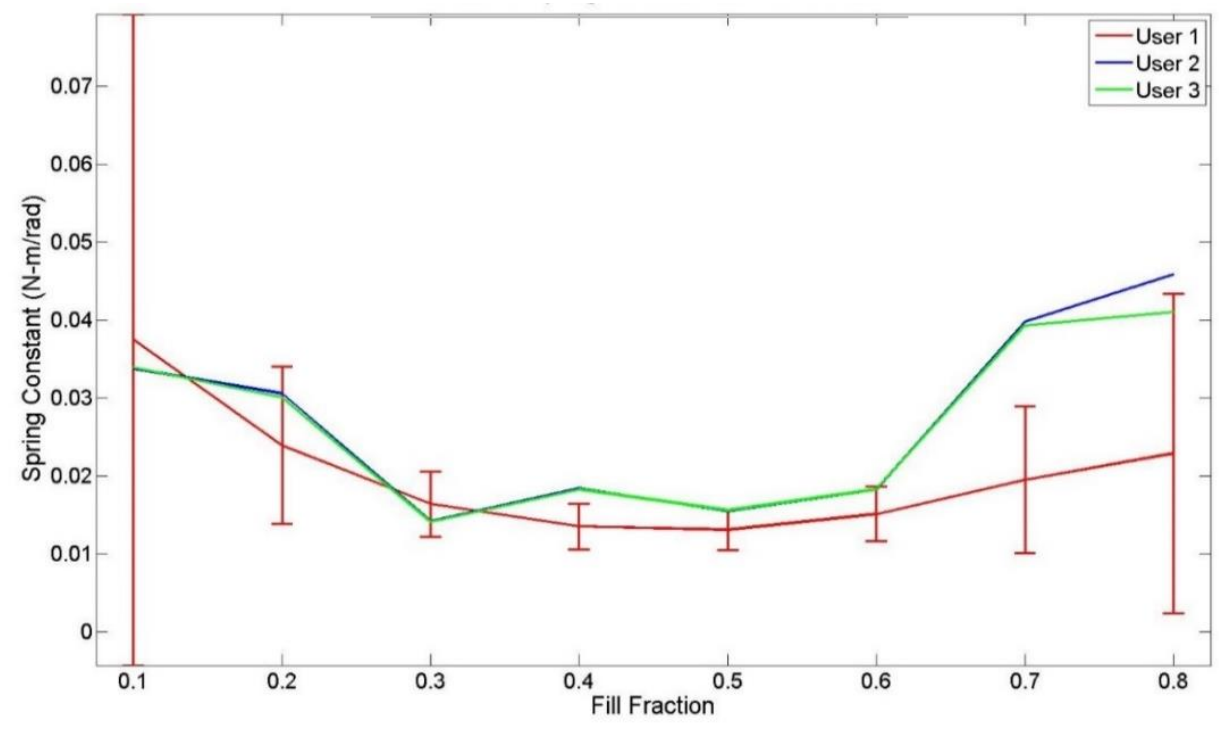

Fig. 26 Oxidizer spring constant vs fill fraction. 


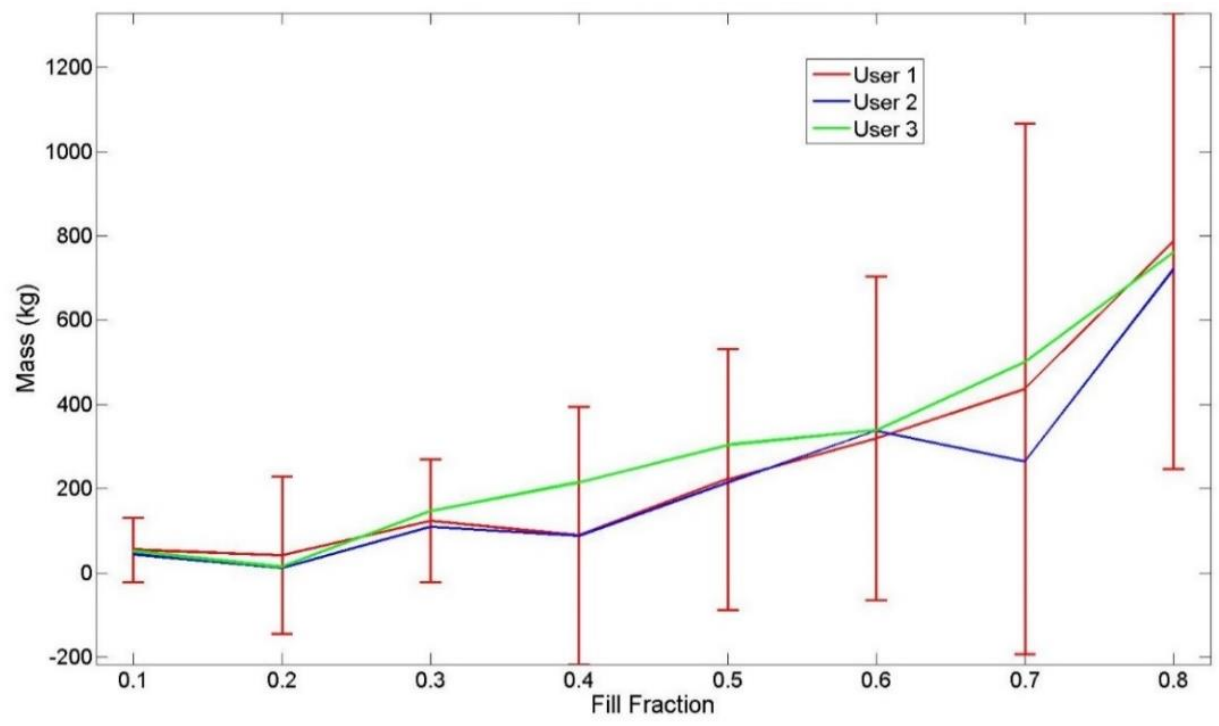

Fig. 27 Oxidizer static mass vs fill fraction.

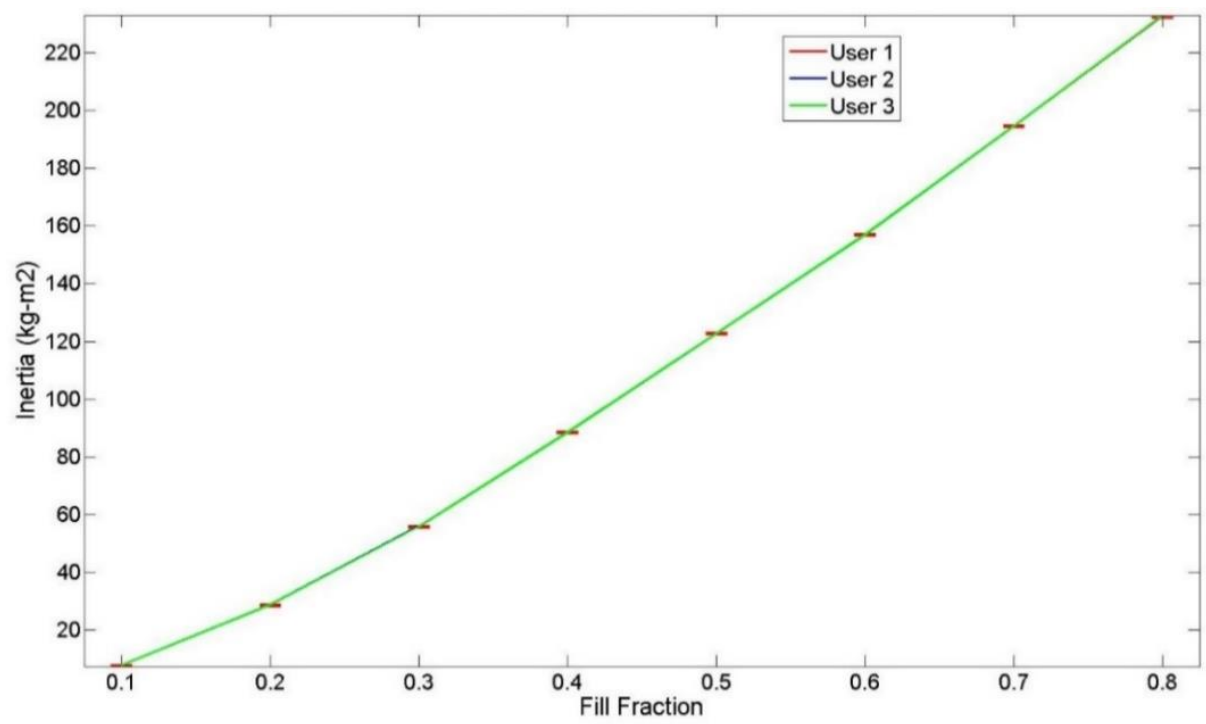

Fig. 28 Oxidizer static vertical axis moment of inertia vs fill fraction. 


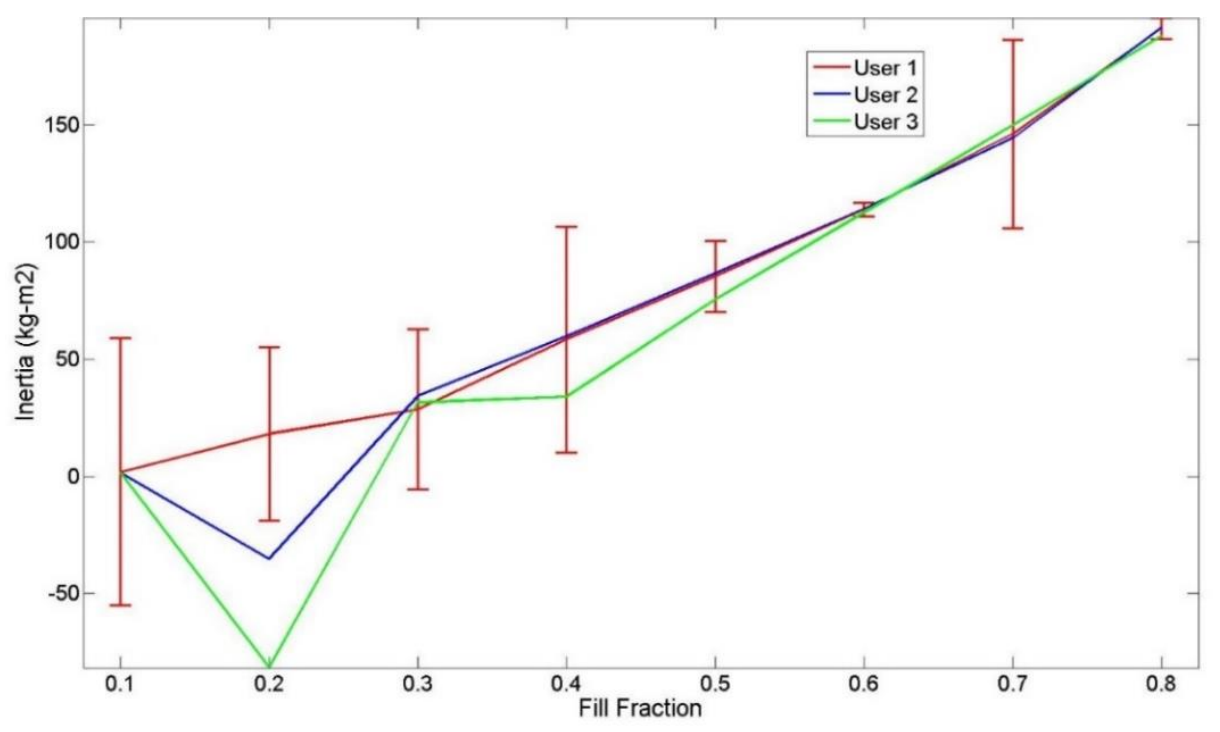

Fig. 29 Oxidizer static horizontal axis moment of inertia vs fill fraction.

These plots indicate that there is a lot of uncertainty in the results, but in most cases several users using the same technique will come to similar answers. There are a few outliers that indicate that the assumed uncertainties may need to be higher. When all of the points that do not fall within the error bars are examined, the uncertainty of the pendulum angle is the input variable that is most likely causing the discrepancy between the error bars and the spread among the three users. The uncertainty of the input pendulum angle ranges from 1.5 to 7 , with the smaller angle uncertainties occurring at the lower fill fractions. Further research will need to be conducted to understand the true uncertainty of this value and if any of the other uncertainties are incorrect.

While the uncertainty calculations help bound the error, and the use of multiple engineers to derive the parameters help validate the repeatability of the approach. Without experimental data or analytical solutions describing low-g propellant slosh, the accuracy of this approach cannot be validated.

\section{Conclusion}

Similar mechanical models consisting of pendulums, springs, and dampers were found for both low and high acceleration cases. High-g cases were modeled with CFD and parameters were found using a MATLAB code written specifically for the purpose of this application. The process of finding an equivalent mechanical model was completed twice in order to analyze the effect of code inputs on the output parameters. Overall, it was found that similar parameters were found for reasonable code inputs. Low-g cases were modeled with Surface Evolver and an equivalent mechanical model was again found. Uncertainty in parameters were found by comparing results from multiple trials. While there were some outliers, the uncertainty values found through uncertainty analysis were sufficient in most cases to explain the different results obtained. Trends were found between the pendulum parameters and the fill fractions for both data sets so that parameters may be interpolated at fill fractions not analyzed in this study. Especially in high-g cases, changes in behavior in the trends typically occur at locations where the PMD and tank geometries change most rapidly.

[1] Brakke, K., "Surface Evolver Overview," Surface Evolver Documentation [online], http://facstaff.susqu.edu/brakke/evolver/html/intro.htm\#overview [retrieved 19 May 2018].

[2] Enright, P. J. and Wong, E. C., "Propellant Slosh Models for the Cassini Spacecraft," AIAA Astrodynamics Conference, Scottsdale, AZ, USA, 1994, pp. 186-195.

[3] Dodge, F. T., "The New "Dynamic Behavior of Liquids In Moving Containers,"” Southwest Research Institute, San Antonio, TX, 2000.

[4] Michell, R. C. et. al., "Engineering Properties of Rocket Propellants," Air Force Rocket Propulsion Laboratory, AD-771 580, Springfield, VA, November 1973.

[5] Ng, W. and Benson, D., "Two-Pendulum Model of Propellant Slosh in Europa Clipper PMD Tank," Thermal and Fluids Analysis Workshop, Report Number GSFC-E-DAA-TN45416, August 2017. 